"Cross-Cultural Invariance of the Mental Toughness Inventory Among Australian, Chinese, and Malaysian Athletes: A Bayesian Estimation Approach" by Gucciardi DF et al.

Note. This article will be published in a forthcoming issue of the Journal of Sport \& Exercise Psychology. The article appears here in its accepted, peer-reviewed form, as it was provided by the submitting author. It has not been copyedited, proofread, or formatted by the publisher.

Section: Article

Article Title: Cross-Cultural Invariance of the Mental Toughness Inventory Among Australian, Chinese, and Malaysian Athletes: A Bayesian Estimation Approach

Authors: Daniel F. Gucciardi ${ }^{1}$, Chun-Qing Zhang ${ }^{2}$, Vellapandian Ponnusamy ${ }^{3}$, Gangyan $\mathrm{Si}^{4}$, and Andreas Stenling 5

Affiliations: ${ }^{1}$ School of Physiotherapy and Exercise Science, Curtin University, Perth, WA, Australia. ${ }^{2}$ Department of Physical Education, Hong Kong Baptist University. ${ }^{3}$ Institut Sukan Negara, National Sports Institute of Malaysia. ${ }^{4}$ Department of Health and Physical Education, Hong Kong Institute of Education. ${ }^{5}$ Department of Psychology, Umeå University, Umeå, Sweden.

Journal: Journal of Sport \& Exercise Psychology

Acceptance Date: March 5, 2016

(C)2016 Human Kinetics, Inc.

DOI: http://dx.doi.org/10.1123/jsep.2015-0320 
"Cross-Cultural Invariance of the Mental Toughness Inventory Among Australian, Chinese, and Malaysian Athletes: A Bayesian Estimation Approach" by Gucciardi DF et al.

Journal of Sport \& Exercise Psychology

(C) 2016 Human Kinetics, Inc.

Running head: Cross-cultural invariance of the MTI

\section{Cross-Cultural Invariance of the Mental Toughness Inventory among Australian, Chinese, and Malaysian Athletes: A Bayesian Estimation Approach}

Daniel F. Gucciardi ${ }^{1 *}$, Chun-Qing Zhang ${ }^{2}$, Vellapandian Ponnusamy ${ }^{3}$, Gangyan $\mathrm{Si}^{4}$, Andreas

$$
\text { Stenling } 5
$$

${ }^{1}$ School of Physiotherapy and Exercise Science, Curtin University

${ }^{2}$ Department of Physical Education, Hong Kong Baptist University

${ }^{3}$ Institut Sukan Negara, National Sports Institute of Malaysia

${ }^{4}$ Department of Health and Physical Education, Hong Kong Institute of Education

${ }^{5}$ Department of Psychology, Umeå University

Author Notes

*Address correspondence to Daniel Gucciardi, School of Physiotherapy and Exercise Science, Curtin University, GPO Box U1987, Perth, Australia, 6845. Email:

\section{daniel.f.gucciardi@gmail.com}

Funding statement. Daniel Gucciardi is supported by a Curtin Research Fellowship. Data collection in Malaysia was supported by a grant from Institut Sukan Negara (ISNRG 012014-07-2014). 
"Cross-Cultural Invariance of the Mental Toughness Inventory Among Australian, Chinese, and Malaysian Athletes: A Bayesian Estimation Approach" by Gucciardi DF et al.

Journal of Sport \& Exercise Psychology

(C) 2016 Human Kinetics, Inc.

\begin{abstract}
The aims of this study were to assess the cross-cultural invariance of athletes' self-reports of mental toughness, and introduce and illustrate the application of approximate measurement invariance using Bayesian estimation for sport and exercise psychology scholars. Athletes from Australia $\left(n=353, M_{\text {age }}=19.13, S D=3.27\right.$, males $\left.=161\right)$, China $\left(n=254, M_{\text {age }}=17.82, S D=\right.$ 2.28 , males $=138)$, and Malaysia $\left(n=341, M_{\text {age }}=19.13, S D=3.27\right.$, males $\left.=200\right)$ provided a cross-sectional snapshot of their mental toughness. The cross-cultural invariance of the mental toughness inventory in terms of (i) the factor structure (configural invariance), (ii) factor loadings (metric invariance), and (iii) item intercepts (scalar invariance) was tested using an approximate measurement framework with Bayesian estimation. Results indicated that approximate metric and scalar invariance was established. From a methodological standpoint, this study demonstrated the usefulness and flexibility of Bayesian estimation for single-sample and multi-group analyses of measurement instruments. Substantively, the current findings suggest that the measurement of mental toughness requires cultural adjustments to better capture the contextually-salient (emic) aspects of this concept.
\end{abstract}

Keywords: approximate measurement invariance; Bayesian; cross-cultural psychology; cultural sport psychology; mentally tough 
"Cross-Cultural Invariance of the Mental Toughness Inventory Among Australian, Chinese, and Malaysian Athletes: A Bayesian Estimation Approach" by Gucciardi DF et al.

Journal of Sport \& Exercise Psychology

(C) 2016 Human Kinetics, Inc.

Conceptualized as a psychological resource that underpins one's self-regulatory capacity to attain and sustain self- (e.g., goals) or externally-referenced standards (e.g., beating an opponent) despite varying degrees of situational demands or stressors (Gucciardi, Hanton, Gordon, Mallett, \& Temby, 2015; Hardy, Bell, \& Beattie, 2014), the concept of mental toughness has received increased attention over the past two decades (for a review, see Gucciardi \& Hanton, in press). With few exceptions (e.g., Kuan \& Roy, 2007), however, the majority of research on mental toughness has been conducted within Western contexts using samples considered representative of these cultures (Gucciardi \& Gordon, 2011). Thus, there remains a need to examine the cultural relevance of mental toughness. Broadly speaking, there are three major goals for cross-cultural psychology (Berry, 1989): first, to transport and test existing psychological concepts, models, and measures in new cultures to shed light on the extent to which they generalize (etic); second, to examine concepts from within a single culture to generate new information regarding the contextually-salient aspects of phenomena (emic); and third, to integrate knowledge regarding the contextual roots of a phenomenon within a specific culture (emic) with information regarding the consistencies and variations across different cultures (etic). This study is concerned with the first of these goals, namely consideration of the measurement of mental toughness as a universal concept through an examination of its transfer from Western to Asian cultures.

\section{Measurement of Mental Toughness}

Over the past two decades, there have been several attempts to develop and validate tools designed to assess the concept of mental toughness (for a review, see Gucciardi, Mallett, Hanrahan, \& Gordon, 2011). We employed the mental toughness index (MTI; Gucciardi, Hanton et al., 2015) for the purposes of this study, given its sound theoretical base and construct validity evidence. Theoretically, the concept of mental toughness as captured by the MTI is 
"Cross-Cultural Invariance of the Mental Toughness Inventory Among Australian, Chinese, and Malaysian Athletes: A Bayesian Estimation Approach" by Gucciardi DF et al.

Journal of Sport \& Exercise Psychology

(c) 2016 Human Kinetics, Inc.

informed by perspectives of stress, coping, and adversity in that it is hypothesized to represent a "resource caravan" (Hobfoll, 2002) pertinent to the process by which individuals deal with stressors and adversities. Through a series of five independent but related studies across multiple achievement contexts (e.g., sport, education), Gucciardi, Hanton, and colleagues provided initial evidence to support this theoretical perspective of mental toughness. First, they demonstrated that mental toughness is best conceptualized as unidimensional rather than a multidimensional construct (Study 2; i.e., poor discriminant validity among several resources, such as self-belief, self-regulation, and optimism). Second, they provided support for the nomological network of mental toughness, including theoretically consistent associations with stress and coping (Study 3), as well as subjective (i.e., academic and social goal progress; Study 4) and objective performance (informant-rated performance in Study 3; special forces selection test in Study 5). Finally, using a weekly diary study design (Study 4), they showed that mental toughness is best conceptualized as a state-like construct that encompasses stable properties yet can vary depending on situational demands. Subsequent research has provided additional support for the construct validity of the MTI. Mahoney, Gucciardi, Ntoumanis, and Mallett (2014) showed that self-reported mental toughness predicted better race performance among a sample of 221 adolescent cross-country runners $(B=.39,95 \%$ CI $[.72, .05])$. Beyond the sporting context, researchers have shown that mental toughness, as measured using the MTI, moderates the physical activity intention-behavior gap among community participants and undergraduate students $(N=117$; Hannan, Moffitt, Neumann, \& Thomas, 2015) and people with knee pain $(N=136$; Gucciardi, in press). Thus, further tests of the construct validity of the MTI appear warranted, as it has the potential to underpin theoretically-informed research. 
"Cross-Cultural Invariance of the Mental Toughness Inventory Among Australian, Chinese, and Malaysian Athletes: A Bayesian Estimation Approach" by Gucciardi DF et al.

Journal of Sport \& Exercise Psychology

(C) 2016 Human Kinetics, Inc.

\section{Cross-Cultural Perspectives on Mental Toughness}

There are both practical and substantive implications of research that tests the validity of measurement instruments in cultures and languages that have not yet been the focus of empirical research on scientific concepts. Substantively, such research can provide insight into the boundary conditions regarding theories of psychological phenomena. For example, is mental toughness a universal concept that generalizes to non-Western cultures? Do some theoretical features of mental toughness (e.g., unidimensional structure) generalize across cultures but not others (e.g., within-person stability)? From a practical perspective, validated scales offer scholars and practitioners tools for their toolbox for the assessment of psychological concepts. This latter point is particularly important, given the continued use of tools that have been found to be invalid for the assessment of mental toughness (e.g., Gucciardi, Hanton, \& Mallett, 2013; Middleton et al., 2004). Thus, there is much to be gained from examinations of the degree to which concepts such as mental toughness are invariant across different cultures.

Given the paucity of theoretical discussions and empirical work on the cultural aspects of mental toughness, we drew from personality theory as a conceptual perspective because most scholars contend that mental toughness represents an aspect of psychological individuality (e.g., Gucciardi, Hanton, et al., 2015; Hardy et al., 2014). Within the context of an integrative perspective of personality (McAdams \& Pals, 2006), psychological individuality is said to exist across three separate yet related layers of understanding including dispositional traits (i.e., temporal and contextual consistencies of personality, such as the 'Big Five'), characteristic adaptations (i.e., contextually or socially salient expressions of dispositional traits, such as motives, goals, coping styles), and self-defining life narratives (i.e., internalized 
"Cross-Cultural Invariance of the Mental Toughness Inventory Among Australian, Chinese, and Malaysian Athletes: A Bayesian Estimation Approach" by Gucciardi DF et al.

Journal of Sport \& Exercise Psychology

(C) 2016 Human Kinetics, Inc.

and evolving personal narratives that make sense of one's past, present, and future selves) ${ }^{1}$. There is preliminary evidence to suggest that the motivational features of mental toughness are expressed across all three layers of personality (Gucciardi, Jackson, Hanton, \& Reid, 2015). Nevertheless, the bulk of evidence supports a conceptualization of mental toughness as a characteristic adaptation. For example, cross-sectional interview studies (e.g., Jones, Hanton, \& Connaughton, 2002) and longitudinal survey research (Gucciardi, Hanton et al., 2015) indicates that mental toughness has properties that can endure or vary across contexts and time. Intervention research offers additional support for this perspective, whereby mental toughness is amenable to change and development via systematic efforts that encompass repeated exposure to punishment conditioned stimuli within a multidisciplinary transformational approach (Bell, Hardy, \& Beattie, 2013). Conceptualized as a characteristic adaptation, therefore, culture is expected to influence the operationalization and/or mean levels of mental toughness because it represents a proximal feature of everyday life (McAdams \& Pals, 2006). However, this theoretical expectation has not yet been tested. One of the ways by which scholars can understand the influence of culture is through statistical analyses of individuals' responses to questionnaires that represent operationalizations of psychological concepts.

\section{Exact Versus Approximate Measurement Invariance}

Inherent within a statistical approach is that different types of measurement equivalence or invariance correspond with diverse substantive interpretations regarding the validity of a tool (for reviews, see Millsap, 2011; Vandenberg \& Lance, 2000). Broadly speaking, there are three types of invariance that are of primary interest: configural (i.e., number of factors and corresponding items per factor are the same), metric (i.e., strength of association between an observed variable of its corresponding factor are the same) and scalar invariance (i.e., intercepts

\footnotetext{
${ }^{1}$ Interested readers are referred elsewhere for a comprehensive review of this integrative perspective of personality as it pertains to sport and exercise contexts (Coulter, Mallett, Singer, \& Gucciardi, in press).
} 
"Cross-Cultural Invariance of the Mental Toughness Inventory Among Australian, Chinese, and Malaysian Athletes: A Bayesian Estimation Approach" by Gucciardi DF et al.

Journal of Sport \& Exercise Psychology

(C) 2016 Human Kinetics, Inc.

of observed variables on their latent factor are the same; Vandenberg \& Lance, 2000). Configural invariance permits the conclusion that the same latent factor(s) are captured in the target groups; metric invariance implies that the same meaning is ascribed to the latent factor(s), and therefore comparisons can be made across the groups with regard to the relations between the target factor(s) and external variables; and scalar invariance tells us that the item scores have the same scaling across the groups, and therefore differences are due to the latent factor rather than differential item functioning making comparisons of latent means possible (Dimitrov, 2010).

Traditionally, sport and exercise psychology researchers have approached the task of testing measurement invariance within a confirmatory factor analysis (CFA) framework (for a review, Estabrook, 2012). Within the context of CFA and the independent clusters model (ICM), each observed variable is regressed on one latent factor only and is therefore considered to be explained by just one construct, with all nontarget loadings and residual covariances constrained to zero (McDonald, 1999). However, the highly restrictive nature of this modeling approach often results in measures of psychological concepts being deemed inadequate because of poor model-data fit and distorted parameter estimates (Marsh et al., 2009). By extension, multi-group CFA permits tests of invariance by comparing more restricted models in which certain parameters of interest (e.g., factor loadings, intercepts) are constrained to be equal across groups with less restricted models where these cross-group constraints are relaxed (Vandenberg \& Lance, 2000). In practice, however, the strict requirement of exact equivalence between groups often results in cases where invariance is not supported (van de Schoot et al., 2013).

Bayesian estimation is a flexible analytical technique that can overcome the limitations of the highly restrictive features of the ICM commonly applied with CFA. Because theoretical or empirical models rarely embody perfectly-specified relations among constructs, Bayesian 
"Cross-Cultural Invariance of the Mental Toughness Inventory Among Australian, Chinese, and Malaysian Athletes: A Bayesian Estimation Approach" by Gucciardi DF et al.

Journal of Sport \& Exercise Psychology

(C) 2016 Human Kinetics, Inc.

estimation enables researchers to model uncertainty in their specifications or operationalizations by replacing exact zero parameters with approximate zeros (i.e., zero mean, small variance; Muthén \& Asparouhov, 2012). Other advantages of Bayesian estimation include the ability to incorporate existing knowledge or beliefs of effects with new data, make intuitive interpretations of the model (e.g., 95\% credibility intervals), obtain better smallsample performance, and test new types of models that are typically unfeasible with frequentist approaches (e.g., maximum-likelihood) or when there are high numbers of parameters (Muthén \& Asparouhov, 2012). Recent research within sport and exercise psychology has demonstrated the usefulness of Bayesian estimation for single-sample analyses of measurement models (e.g., Barnett et al., 2016; Stenling, Ivarsson, Johnson, \& Lindwall, 2015) and structural sequences (e.g., Healy, Ntoumanis, Veldhuijzen van Zanten, \& Paine, 2014; Howle, Dimmock, \& Jackson, 2016) ${ }^{2}$.

Within a Bayesian framework, the usefulness of replacing exact zero parameters with approximate zeros also extends to tests of measurement and structural invariance across groups (Muthén \& Asparouhov, 2013; van de Schoot et al., 2013). Essentially, rather than testing the idea that parameters of interest (e.g., factor loadings, intercepts) are exactly equal across groups, Bayesian estimation allows for some "wiggle room" with regard to invariant parameters via "the degree of precision of the prior" (van de Schoot et al., 2013, p. 2). In so doing, small non-zero differences between groups are permitted while constraining parameters to be close to zero (i.e., zero mean, small variance priors), thereby reducing the likelihood that model-data fit suffers (Muthén \& Asparouhov, 2013; van de Schoot et al., 2013). For example, a prior variance of .05 around a zero mean represents the belief that $95 \%$ of the distribution of

\footnotetext{
${ }^{2}$ Interested readers are referred elsewhere for an overview and didactical illustration of Bayesian estimation within the context of the sport and exercise sciences (Gucciardi \& Zyphur, 2016).
} 
"Cross-Cultural Invariance of the Mental Toughness Inventory Among Australian, Chinese, and Malaysian Athletes: A Bayesian Estimation Approach" by Gucciardi DF et al.

Journal of Sport \& Exercise Psychology

(C) 2016 Human Kinetics, Inc.

non-invariance of the parameter between groups lies between $\pm .44^{3}$. Simulation research has shown that there are minimal risks to substantive conclusions when small variations in parameter estimates are permitted between groups (van de Schoot et al., 2013). Recent research has demonstrated the usefulness of approximate measurement invariance when compared with exact equivalence for cross-national investigations of concepts such as happiness (Bujacz, Vitters $\varnothing$, Huta, \& Kaczmarek, 2014), human values (Cieciuch, Davidov, Schmidt, Algesheimer, \& Schwartz, 2014), and attitudes toward immigration (Davidov et al., 2015). As there is only one study to date within the field of sport and exercise psychology literature (Chan et al., in press), there is a need for additional research to introduce and showcase the application of approximate measurement invariance to scholars interested in psychological concepts within sport and exercise settings.

\section{Purposes of the Present Study}

In summary, the substantive purpose of this study was to examine the cross-cultural invariance of mental toughness across three different cultural groups of athletes. Australian athletes were chosen as the representative group for Western culture because it has been a primary location for research on mental toughness, including the original context where the mental toughness inventory was developed and validated (Gucciardi, Hanton et al., 2015). We targeted Malaysian and Chinese athletes as examples of Asian cultures because mental toughness is a topic of interest in these regions (e.g., Kuan \& Roy, 2007; Xinyi, Smith, \& Adegbola, 2004). Malaysian society in modern times is increasingly being shaped by both western and eastern cultures (Merriam \& Mohamad, 2000), whereas China represents a collectivist society ( $\mathrm{Si}$, Duan, Li, Zhang, \& Su, 2015). Thus, there may be unique variations in the degree to which individuals are exposed to stressors that may underpin the formation of

\footnotetext{
${ }^{3}$ The $95 \%$ interval around a mean is calculated as 1.96 times the square root of the variance, such that $95 \%$ of the area of a normal distribution is within 1.96 standard deviations of the mean.
} 
"Cross-Cultural Invariance of the Mental Toughness Inventory Among Australian, Chinese, and Malaysian Athletes: A Bayesian Estimation Approach" by Gucciardi DF et al.

Journal of Sport \& Exercise Psychology

(c) 2016 Human Kinetics, Inc.

individuals' perspectives of mental toughness, the type of information that is conveyed between members regarding the psychological content of mental toughness, and the extent to which mental toughness is deemed a valuable construct. For example, the emphasis on a grouporiented culture within collectivist societies, where pursuits of group interests and objectives are highly valued and considered the cultural bind among its people (Triandis, 1995), may give precedence to group roles over individual traits such as mental toughness. From a methodological standpoint, we aimed to illustrate an alternative approach for conducting invariance analyses, namely the concept of approximate measurement invariance (Muthén \& Asparouhov, 2013).

\section{Methods}

\section{Participants}

Athletes from three different cultures participated: (i) 353 Australian athletes aged 15 to 26 years $(M=19.13, S D=3.27)$, which included 161 males and 192 females; (ii) 341 Malaysian athletes aged 15 to 26 years $(M=19.13, S D=3.27)$, which included 200 males and 140 females (1 participant did not report gender); and (iii) 254 Chinese athletes aged 15 to 26 years $(M=17.82, S D=2.28)$, which included 138 males and 114 females ( 2 participants did not report gender). Athletes were drawn from a range of individual (e.g., boxing, cycling) and team (e.g., field hockey, soccer) sports. The sample consisted of athletes who were primarily involved in national $(65 \%)$ or international (15\%) level competitions, and had between 1 and 17 years of competitive experience in their sport $(M=8.98, S D=3.64)$.

\section{Measures}

We used the 8-item mental toughness inventory (MTI; Gucciardi, Hanton et al., 2015) to measure self-reported mental toughness. Participants are asked to indicate how true each of the statements (e.g., "I strive for continued success" and "I am able to regulate my focus when 
"Cross-Cultural Invariance of the Mental Toughness Inventory Among Australian, Chinese, and Malaysian Athletes: A Bayesian Estimation Approach" by Gucciardi DF et al.

Journal of Sport \& Exercise Psychology

(C) 2016 Human Kinetics, Inc.

performing tasks") is an indication of how they typically think, feel, and behave as an athlete using a 7 -point response scale $(1=$ false, $100 \%$ of the time to $7=$ true, $100 \%$ of the time $)$. Consistent with recommendations for test adaptation (Hambleton \& Kanjee, 1995), the Malay and Chinese versions of the MTI were developed from the English version using forward- and back-translation procedures by an independent translator at both stages of the process. The Malay and Chinese versions of the MTI are provided in the supplementary material.

\section{Procedures}

All study procedures were approved by [name blinded for peer-review] human research ethics committee. Participants were recruited via sporting organizations, whereby one of the researchers contacted a representative of the organization (e.g., High Performance Manager, Research Director) to provide details on the aims and procedures of the study, and request permission to approach coaches and athletes. Upon receipt of gatekeeper approval, the researchers liaised with the coach of each team or squad to organize a convenient time and location to distribute the survey package ${ }^{4}$ to the athletes in person. Athletes were informed about the nature of the study and provided their consent by ticking a box in the survey package. The survey package was completed either at the training venue prior to, or after a practice session; in situations where the time demands of a training session could not accommodate the former method, athletes took the survey home with them, completed it, and returned it at the next training session.

\section{Statistical Analyses}

The primary analyses were conducted in two phases. First, we tested the factorial validity of the hypothesized unidimensional structure of the MTI separately for each country.

\footnotetext{
${ }^{4}$ The survey package contained several other measures not reported in this paper; these data will be the subject of future papers.
} 
"Cross-Cultural Invariance of the Mental Toughness Inventory Among Australian, Chinese, and Malaysian Athletes: A Bayesian Estimation Approach" by Gucciardi DF et al.

Journal of Sport \& Exercise Psychology

(C) 2016 Human Kinetics, Inc.

Second, a sequential model testing approach was adopted to test the cross-cultural invariance of the MTI in terms of (i) the factor structure (configural invariance), (ii) factor loadings (metric invariance), and (iii) item intercepts (scalar invariance; for a review of measurement invariance, see Cheung \& Rensvold, 2002). We conducted both analytical phases using a Bayesian structural equation modeling and approximate measurement invariance (Muthén \& Asparouhov, 2012, 2013). In Bayesian estimation, default priors were employed for factor loadings (normal distribution with $\mu=0, \sigma^{2}=10^{10}$ ), whereas residual covariances were modeled using zero mean, small variance priors $\left(\mu=0, \sigma^{2}=.006\right)$ to account for influences on observed variables that are not captured in the latent mental toughness factor (Asparouhov, Muthén, \& Morin, 2015). Latent factor reliability estimates were computed using McDonald's (1970) omega coefficient $(\omega)$.

All analyses were performed using Mplus 7.4 (Muthén \& Muthén, 1998-2015). Missing data $(<0.23 \%)$ were handled with the Gibbs sampler that treats the missing observations as unknown values to be estimated and the algorithm used will correctly estimate the model under the missing at random (MAR) assumption (Asparouhov \& Muthén, 2010). We implemented Bayesian models using Markov Chain Monte Carlo (MCMC) simulation procedures with a Gibbs sampler, and specified a fixed number of 150,000 iterations each for four MCMC chains (the first half are used as the 'burnin phase' as default). Model convergence was assessed using statistical criteria (i.e., potential scale reduction factor < 1.1; Asparouhov \& Muthén, 2010) and visual inspection of trace plots to ensure multiple chains converged to a similar target distribution (van de Schoot et al., 2014). Model-data fit within Bayesian estimation is interpreted according to two statistical criteria: (i) posterior predictive $p$ value (PPP value) where values around .50 indicate a well-fitting model, whereas small values (e.g., $<.05)$ suggests poor model-data fit; and (ii) the $95 \%$ confidence interval for the difference of the observed and replicated $\chi^{2}$ values, which should encompass zero for a well-fitting model 
"Cross-Cultural Invariance of the Mental Toughness Inventory Among Australian, Chinese, and Malaysian Athletes: A Bayesian Estimation Approach" by Gucciardi DF et al.

Journal of Sport \& Exercise Psychology

(C) 2016 Human Kinetics, Inc.

(Muthén \& Asparouhov, 2012). In the Bayesian approach to approximate measurement invariance, the average distance between the parameters of interest (e.g., loadings, intercepts) is assumed to be zero, yet small variations in the degree of precision are permitted via the prior probability distribution. We specified three different levels of approximation (variance priors of $.05, .01$, and .005) for the factor loadings (metric) or intercepts (scalar) alone, or their combination in the same model (metric and scalar). Parameters that differ significantly from the priors between the groups are flagged in the Mplus output. The deviance information criterion (DIC) was used to compare measurement invariance models with Bayesian estimation, such that a lower value indicates a better fitting model (Asparouhov et al., 2015). All Mplus syntax files are provided in the supplementary material.

\section{Results}

\section{Preliminary Analyses}

Item level statistics for each cultural group is presented in Table 1. The positive endorsement (i.e., mean score for all eight items greater than 5 on a 1-7 response scale ${ }^{5}$ ) and variances of the mental toughness items are broadly comparable across all three groups, though the mean response is typically higher for Malaysian athletes. For all three groups, the distributional properties approximate a normal distribution; however, there is evidence that the responses to some items (e.g., "I strive for continued success") cluster around the mean for the Malaysian athletes (i.e., leptokurtic).

\section{Factorial Validation of the MTI}

Analyses indicated that the probability of the 8-item unidimensional model, given the data, was excellent in the Australian (PPP $=.499, \Delta$ observed and replicated $\chi^{2} 95 \%$ CI [-25.96,

\footnotetext{
${ }^{5}$ An inspection of the raw data for each cultural group revealed that participants utilized the full response scale, albeit with the majority of responses recorded on 4, 5, 6 and 7 .
} 
"Cross-Cultural Invariance of the Mental Toughness Inventory Among Australian, Chinese, and Malaysian Athletes: A Bayesian Estimation Approach" by Gucciardi DF et al.

Journal of Sport \& Exercise Psychology

(C) 2016 Human Kinetics, Inc.

26.65]), Malaysian $\left(\mathrm{PPP}=.496, \Delta\right.$ observed and replicated $\chi^{2} 95 \%$ CI $\left.[-26.18,26.79]\right)$, and

Chinese athletes $\left(\mathrm{PPP}=.499, \Delta\right.$ observed and replicated $\chi^{2} 95 \%$ CI $\left.[-26.21,26.50]\right)$. Visual inspection of trace plots and an examination of the PSR development over iterations (i.e., smooth decrease in PSR, last few thousand iterations were close to 1) provided support for convergence of all models. Across all three samples, factor loadings and latent factor reliability estimates were excellent (see Table 2). Of the 28 residual covariances, none were statistically significant across all three samples (i.e., 95\% credibility interval encompassed zero).

\section{Cross-Cultural Invariance of the MTI}

An overview of the model-data fit indices for the Bayesian approach is detailed in Table 6. Visual inspection of trace plots and an examination of the PSR development over iterations (i.e., smooth decrease in PSR, last few thousand iterations were close to 1) provided support for convergence of all models. Tests of approximate measurement invariance were performed using three different levels of approximation (variance priors of $.05, .01$, and .005). With regard to factor loadings (metric invariance), all three degrees of wiggle room fit the data well; the DIC supported a variance of .05 as the best fitting model. Allowing for a prior variance of .05 or .01 between the intercepts (scalar invariance) but not .005 resulted in an acceptable model fit; the DIC indicated a variance of .05 as the best fitting model. Similarly, when approximate measurement invariance was applied to both the factor loadings and item intercepts (metric and scalar invariance), a prior variance of .05 or .01 was deemed acceptable, whereas .005 did not fit the data well; the DIC supported a variance of .05 for both sets of parameters as the best fitting model. Deviations from the mean for factor loadings and intercepts for each of the three athlete groups is presented in Table 7. These findings indicated that several item-level scores differed significantly from the priors across all three groups; for example, whereas Australian athlete scored lower than the mean for item 1 ("I believe in my ability to achieve my goals"), 
"Cross-Cultural Invariance of the Mental Toughness Inventory Among Australian, Chinese, and Malaysian Athletes: A Bayesian Estimation Approach" by Gucciardi DF et al.

Journal of Sport \& Exercise Psychology

(C) 2016 Human Kinetics, Inc.

Malaysian athletes scored higher than the mean. Akin to the partial measurement invariance approach with frequentist estimation, the best fitting approximate metric and scalar invariance model (variance of .05) was refined in a second step (Muthén \& Asparouhov, 2013). Specifically, parameters found to be invariant were forced to be exactly equal, whereas parameters that were different between groups were released and freely estimated (i.e., intercepts of items 1, 3, 4, 7 and 8 for Malaysian athletes; and 5, 6, 7, and 8 for Chinese athletes). This model was a good fit with the data, and deemed a better fitting model than the approximate metric and scalar invariance model (see Table 6).

\section{Discussion}

In this study, we examined whether athletes' self-reports of mental toughness exhibited measurement invariance across three cultural groups, namely Australian, Chinese, and Malaysian athletes. We also provided an illustration of approximate measurement invariance within a Bayesian estimation framework, which is an alternative method to the common frequentist approach to measurement invariance analyses that tests strict zero differences between groups. This study is among the first to address these substantive (i.e., cross-cultural invariance of mental toughness) and methodological issues (i.e., introduction and illustration of approximate measurement invariance) within the sport and exercise psychology literature. Results indicated that the same unidimensional latent factor (configural) and meaning is ascribed to the mental toughness construct (metric) across all three groups. Specifically, the approximate approach to measurement invariance showed that the inclusion of small differences forced to be close to zero produced a good fit with the data, thereby supporting approximate metric and scalar invariance. 
"Cross-Cultural Invariance of the Mental Toughness Inventory Among Australian, Chinese, and Malaysian Athletes: A Bayesian Estimation Approach" by Gucciardi DF et al.

Journal of Sport \& Exercise Psychology

(c) 2016 Human Kinetics, Inc.

\section{Cross-Cultural Invariance of Mental Toughness}

The dimensionality of mental toughness has been a key focus of theoretical (e.g., Mahoney, Ntoumanis, Mallett, \& Gucciardi, 2014) and empirical work (e.g., Gucciardi, Hanton et al., 2015) in recent years. The findings of early research suggested that mental toughness may be best conceptualized a multidimensional construct that encompasses a variety of cognitive, emotional, and behavioral dimensions central to high performance or goal attainment despite stressful or challenging circumstances (e.g., Jones et al., 2002). However, attempts to operationalize multidimensional conceptualizations of mental toughness through self-reported questionnaires have been unsuccessful (e.g., Gucciardi et al., 2013; Middleton et al., 2004). Recent research has supported a unidimensional conceptualization of mental toughness in terms of observable behaviors (Hardy et al., 2014) and unobservable personal attributes (Gucciardi, Hanton et al., 2015). The results of the current study support and extend this recent evidence to indicate that a unidimensional structure is a viable representation of mental toughness for both Western and non-Western cultures.

To date, there has been no research on the invariance of mental toughness across different cultural groups, despite the importance of these tests for substantive and methodological features of scientific inquiry (Cheung \& Rensvold, 2002; Vandenberg \& Lance, 2000). Methodologically, assuming that a construct is invariant across sub-groups of a population (e.g., cultural background) or different methods (e.g., online versus hardcopy) may result in findings that do not accurately reflect real group differences and therefore are deemed invalid (e.g., distorted means). This methodological issue also has important implications for substantive conclusions from cross-cultural research; that is, before one can make valid comparisons of group means or associations between mental toughness and external variables (e.g., goal attainment, objective performance), it is necessary to demonstrate that an instrument is invariant across these cultural groups. Substantively, detecting measurement non-invariance 
"Cross-Cultural Invariance of the Mental Toughness Inventory Among Australian, Chinese, and Malaysian Athletes: A Bayesian Estimation Approach" by Gucciardi DF et al.

Journal of Sport \& Exercise Psychology

(c) 2016 Human Kinetics, Inc.

(e.g., interpretation of items) might reflect between-group differences that are of theoretical interest. As the first study to directly examine cross-cultural aspects of mental toughness, our results provide preliminary evidence regarding the stability of the unidimensional structure and definitions and meanings of the concept (i.e., strength of association between the items and latent mental toughness factor). Approximate measurement invariance analyses provided support for metric and scalar invariance when there is a $95 \%$ chance the absolute loading and intercept difference is equal to or smaller than .22 [i.e., sqrt (.05)] or .10 [i.e., sqrt (.01)]. Nevertheless, there were instances in which item intercepts of specific cultural groups differed significantly from these prior distributions (see Table 7). These results support a conceptualization of mental toughness as a characteristic adaptation (McAdams \& Pals, 2006) because culture appears to have an influence on mean levels of responses.

Although we did not directly examine possible explanations for the source(s) of differences in the origin or intercept of MTI responses in this study, it is important to consider reasons for non-invariance that may explain these differences and guide future research. Bias, which occurs when scores on test items do not correspond with the target construct within a particular application or comparison (e.g., Australian versus China), may arise because of issues relating to the construct, method, or item content (for a review, see van de Vijver \& Tanzer, 2004). With regard to construct bias, differences in the meaningfulness of the construct between cultural groups may occur because the attribute is partially defined, item indicators are differentially appropriate or poorly sampled, or the relevant features of the construct are inadequately covered. For example, the transportation of a Westernized measure of mental toughness into Chinese culture is unlikely to fully appreciate key sociocultural factors related to holistic/dialectic thinking style (e.g., harmony with environment), keeping face (e.g., politeness, non-confrontational behavior), collectivist characteristics (e.g., prioritize collectivist interests), and authoritative characteristics (e.g., coach authority) (Si et al., 2015). 
"Cross-Cultural Invariance of the Mental Toughness Inventory Among Australian, Chinese, and Malaysian Athletes: A Bayesian Estimation Approach" by Gucciardi DF et al.

Journal of Sport \& Exercise Psychology

(C) 2016 Human Kinetics, Inc.

It is therefore unsurprising that Chinese athletes reported lower mean levels of each item, as mental toughness represents an individualistic personal resource. Aspects of the methodological procedures may also contribute to bias, including the sample (e.g., incompatibility due to individual differences such as motivation, education), instrument (e.g., ambiguous instructions, stimulus, and response format familiarity) or administration processes (e.g., environmental conditions, differential expertise of survey administrators). For example, as some players completed the survey at a training session in close proximity to their teammates and coach, whereas others completed the survey individual at home, we cannot rule out the possibility of social desirability effects for those athletes who completed the survey in front of others (cf. Richman, Kiesler, Weisband, \& Drasgow, 1999). Finally, in terms of item bias, distortions typically occur when items have been poorly translated (e.g., linguistic idiosyncrasies) or are ambiguous, there is differential familiarity or appropriateness of item content, or item wording is influenced by culture- or context-specific nuisances (e.g., invokes additional traits) or connotations. For example, at the time of data collection, the Malaysian sport system was going through a major restructure to increase the national prestige of sport and attainment of medals at the Asian, Commonwealth and Olympic games. With an increased awareness of the importance of a high performance culture through its Podium Program, it may be that the Malaysian athletes in our study reported higher item means because they perceived these psychological attributes to be hallmarks of athletes who encapsulate this new performance system (e.g., socially desirable responses). It is important that these potential sources of bias are examined in future research (for guidance, see van de Vijver \& Tanzer, 2004). 
"Cross-Cultural Invariance of the Mental Toughness Inventory Among Australian, Chinese, and Malaysian Athletes: A Bayesian Estimation Approach" by Gucciardi DF et al.

Journal of Sport \& Exercise Psychology

(C) 2016 Human Kinetics, Inc.

\section{Approximate Measurement Invariance}

The methodological focus of this study involved the introduction and an illustration of approximate measurement invariance within a Bayesian framework (Muthén \& Asparouhov, 2013). Two key strengths of Bayesian estimation were illustrated in this study. The first strength of Bayesian estimation relates to the ability to model residual covariances. Covariances among item residuals represent shared sources of influence that cannot be attributed to the underlying latent construct, such as an omitted or unmeasured latent factor, overlap in item content, or response styles such as social desirability, yea-saying or nay-saying (Aish \& Jöreskog, 1990). When fixed to zero, misspecified residual covariances may negatively affect model-data fit. However, when these parameters are released and made completely free, such post hoc modifications may result in underidentified models and therefore an inability for model assessment to take place, or risk capitalization on chance (MacCallum, Roznowski, \& Necowitz, 1992). Bayesian estimation can alleviate these concerns, whereby residual covariances can be approximately fixed to zero using small informative priors (i.e., zero mean, small variance; Asparouhov et al., 2015).

Bayesian estimation also offers flexibility with regard to multigroup invariance analyses. Given the post hoc, data-driven nature of partial invariance tests with the exact approach to measurement invariance, it is important to verify such findings with new samples to rule out concerns associated with capitalizing on chance (Vandenberg \& Lance, 2000). The often unrealistic assumption of exact zero differences between groups may negatively affect model-data fit, thus making Bayesian estimation suitable when there may be small differences in parameter estimates between groups, and the inclusion of these discrepancies in model estimation is warranted (van de Schoot et al., 2013). Our results are consistent with these expectations, that is, by replacing the strict requirement of exact zero with approximate zero differences between groups, model fit criteria indicated that approximate metric and scalar 
"Cross-Cultural Invariance of the Mental Toughness Inventory Among Australian, Chinese, and Malaysian Athletes: A Bayesian Estimation Approach" by Gucciardi DF et al.

Journal of Sport \& Exercise Psychology

(c) 2016 Human Kinetics, Inc.

invariance was established with Bayesian estimation. Therefore, the approximate measurement invariance approach can be considered a compromise between the requirement of equivalence of parameters between groups and a well-fitting model (van De Schoot, Schmidt, De Beuckelaer, Lek, \& Zondervan-Zwijnenburg, 2015). Despite these encouraging findings, it is worth noting the differential effects or influence of priors in the current study (e.g., drop in PPP values with more informative priors), and therefore the importance of performing sensitivity analyses when using Bayesian statistics (for an illustration, see Gucciardi \& Zyphur, 2016). It is also important to note that the proposed values of model-data fit for Bayesian statistics have not yet been empirically validated (e.g., PPP value > .05; Muthén \& Asparouhov, 2012), so caution is urged when interpreting them as definitive cuts or 'golden rules'. The recent publication of a 10-item checklist for conducting Bayesian statistics offers sound guidance on these and other issues for applied researchers (Depaoli \& van de Schoot, in press).

\section{Strengths and Limitations}

Strengths of this study include modest sample sizes for each of the three cultural groups, and the application and comparison of two statistical approaches to measurement invariance. Nevertheless, it is important to consider the results of this study in light of its limitations. First, we took an emic approach to understanding cultural aspects of mental toughness in this study, where there is an inherent assumption that the concept generalizes across cultures. The current findings suggest that the measurement of mental toughness requires cultural adjustments to better capture the emic aspects of this concept. Second, we did not examine the extent to which non-invariance of item intercepts (exact) or intercepts that differ significantly from the priors between the groups (approximate) might influence the interpretation of associations between mental toughness and external criteria. Third, as there is no available evidence on the developmental variations in mental toughness, we cannot rule 
"Cross-Cultural Invariance of the Mental Toughness Inventory Among Australian, Chinese, and Malaysian Athletes: A Bayesian Estimation Approach" by Gucciardi DF et al.

Journal of Sport \& Exercise Psychology

(C) 2016 Human Kinetics, Inc.

out the possibility of age differences in conceptualizations of mental toughness among a sample of 15 to 26 year old athletes. Relatedly, there is a need for future research to examine the invariance of mental toughness across genders, and other potentially important demographic variables (e.g., language, sport level). Finally, given that approximate measurement invariance is a relatively new analytical technique, there are many issues pertinent to the interpretation of the current results that require clarification through future research (e.g., minimal number of parameters and the size of the difference, most appropriate prior specification, model fit indices; van de Schoot et al., 2013).

\section{Conclusion}

Developing synergies through statistical modeling has the potential to offer advancements for substantive features of psychological concepts (e.g., universality of a construct) and methodological issues for scientific inquiry (e.g., compromise between ideal and realistic models). This study is the first to examine the cross-cultural invariance of mental toughness in sport, as well as compare zero (or exact) versus approximate measurement invariance within the sport and exercise psychology literature. The methodological focus of this study demonstrated the usefulness and flexibility of Bayesian estimation for single-sample and multi-group analyses of measurement instruments. These findings suggest that researchers and practitioners can use the English, Malay, and Chinese versions of the MTI in future research that seeks to provide insight into the theoretical features of this concept. Nevertheless, it is important that our understanding of the contextually-salient (emic) aspects of mental toughness is refined through future research. 
"Cross-Cultural Invariance of the Mental Toughness Inventory Among Australian, Chinese, and Malaysian Athletes: A Bayesian Estimation Approach" by Gucciardi DF et al.

Journal of Sport \& Exercise Psychology

(C) 2016 Human Kinetics, Inc.

\section{References}

Aish, A. M., \& Jöreskog, K. G. (1990). A panel model for political efficacy and responsiveness: An application in LISREL 7 with weighted least squares. Quality \& Quantity, 19, 716-723. doi:10.1007/BF00152013

Asparouhov, T., \& Muthén, B. (2010). Bayesian analysis using Mplus: Technical implementation. Retrieved from http://www.statmodel.com/download/Bayes3.pdf

Asparouhov, T., Muthén, B., \& Morin, A. J. S. (2015). Bayesian structural equation modeling with cross-loadings and residual covariances: Comments on Stromeyer et al. Journal of Management, 41, 1561-1577. doi:10.1177/0149206315591075

Barnett, L. M., Vazou, S., Abbott, G., Bowe, S. J., Robinson, L. E., Ridgers, N. D., \& Salmon, J. (2016). Construct validity of the pictorial scale of perceived movement skills competence. Psychology of Sport and Exercise, 22, 294-302. doi:10.1016/j.psychsport.2015.09.002

Berry, J. W. (1989). Imposed etics, emics and derived etics: The operationalization of a compelling idea. International Journal of Psychology, 24, 721-735.

Bell, J., Hardy, L., \& Beattie, S. (2013). Enhancing mental toughness and performance under pressure in elite young cricketers: A 2-year longitudinal intervention. Sport, Exercise, and Performance Psychology, 2, 281-297. doi:10.1037/a0033129

Bujacz, A., Vittersø, J., Huta, V., \& Kaczmarek, L. D. (2014). Measuring hedonia and Eudaimonia as motives for activities: Cross-national investigation through traditional and Bayesian structural equation modeling. Frontiers in Psychology, 5: 984. doi:10.3389/fpsyg.2014.00984

Byrne, B. M., Shavelson, R. J., \& Muthén, B. (1989). Testing for the equivalence of factor covariance and mean structures: The issue of partial measurement invariance. Psychological Bulletin, 105, 456-466.

Chan, D. K. C., Ivarsson, A., Stenling, A., Yang, S. X., Chatzisarantis, N. L. D., \& Hagger, M. S. (in press). Response-order effects in survey methods: A randomized controlled crossover study in the context of sport injury. Journal of Sport and Exercise Psychology.

Cheung, G. W., \& Rensvold, R. B. (2002). Evaluating goodness-of-fit indexes for testing measurement invariance. Structural Equation Modeling, 9, 233-255. doi:10.1207/S15328007SEM0902_5.

Cieciuch, J., Davidov, E., Schmidt, P., Algesheimer, R., \& Schwartz, S. H. (2014). Comparing results of an exact vs. an approximate (Bayesian) measurement invariance test: A cross-country illustration with a scale to measure 19 human values. Frontiers in Psychology, 5: 982. doi:10.3389/fpsyg.2014.00982

Coulter, T. J., Mallett, C. J., Singer, R., \& Gucciardi, D. F. (in press). Personality in sport and exercise psychology: Integrating a whole person perspective. International Journal of Sport and Exercise Psychology. doi:10.1080/1612197X.2015.1016085 
"Cross-Cultural Invariance of the Mental Toughness Inventory Among Australian, Chinese, and Malaysian Athletes: A Bayesian Estimation Approach" by Gucciardi DF et al.

Journal of Sport \& Exercise Psychology

(c) 2016 Human Kinetics, Inc.

Davidov, E., Cieciuch, J., Meuleman, B., Schmidt, P., Algesheimer, R., \& Hausherr, M. (2015). The comparability of measurements of attitudes toward immigration in the European Social Survey: Exact versus approximate measurement equivalence. Public Opinion Quarterely, 79, 244-266. doi:10.1093/poq/nfv008

Depaoli, S., \& van de Schoot, R. (in press). Improving transparency and replication in Bayesian statistics: The WAMBS-checklist. Psychological Methods.

Dimitrov, D. M. (2010). Testing for factorial invariance in the context of construct validation. Measurement and Evaluation in Counseling and Development, 43, 121-149. doi:10.1177/0748175610373459

Estabrook, R. (2012). Factorial invariance: Tools and concepts for strengthening research. In G. Tenenbaum, R. C. Eklund, \& A. Kamata (Eds.), Measurement in sport and exercise psychology (pp. 53-63). Champaign, IL: Human Kinetics.

Gucciardi, D.F. (in press). Mental toughness as a moderator of the intention-behaviour gap in the rehabilitation of knee pain. Journal of Science and Medicine in Sport. doi: 10.1016/j.jsams.2015.06.010

Gucciardi, D. F., \& Gordon, S. (2011). Mental toughness in sport: Past, present, and future. In D.F. Gucciardi \& S. Gordon (Eds.), Mental toughness in sport: Developments in research and theory (pp. 233-251). Abingdon, Oxon: Routledge.

Gucciardi, D. F., \& Hanton, S. (in press). Mental toughness: Critical reflections and future considerations. In R.J. Schinke, Kerry R. McGannon, \& B. Smith (Eds.), Routledge International Handbook of Sport Psychology. Routledge.

Gucciardi, D. F., Hanton, S., Gordon, S., Mallett, C. J., \& Temby, P. (2015). The concept of mental toughness: Tests of dimensionality, nomological network, and traitness. Journal of Personality, 83, 26-44. doi:10.1111/jopy.12079

Gucciardi, D. F., Hanton, S., \& Mallett, C. J. (2013). Progressing measurement in mental toughness: A response to Clough, Perry, Earle and Crust. Sport, Exercise and Performance Psychology, 2, 157-172. doi:10.1037/spy0000002

Gucciardi, D. F., Jackson, B., Hanton, S., \& Reid, M. (2015). Motivational correlates of mentally tough behaviors in tennis. Journal of Science and Medicine in Sport, 18, 6771. doi:10.1016/j.jsams.2013.11.009

Gucciardi, D. F., Mallett, C. J., Hanrahan, S. J., \& Gordon, S. (2011). Measuring mental toughness in sport: Current status and future directions. In D. F. Gucciardi \& S. Gordon (Eds.), Mental toughness in sport: Developments in research and theory (pp. 108-132). Abingdon, England: Routledge.

Gucciardi, D. F., \& Zyphur, M. J. (2016). Exploratory structural equation modelling and Bayesian estimation. In N. Ntoumanis \& N.D. Myers (Eds.), An introduction to intermediate and advanced statistical analyses for sport and exercise scientists (pp. 172-194). Chichester, West Sussex: Wiley. 
"Cross-Cultural Invariance of the Mental Toughness Inventory Among Australian, Chinese, and Malaysian Athletes: A Bayesian Estimation Approach" by Gucciardi DF et al.

Journal of Sport \& Exercise Psychology

(C) 2016 Human Kinetics, Inc.

Hambleton, R. K., \& Kanjee, A. (1995). Increasing the validity of cross-cultural assessments: Use of improved methods for test adaptations. European Journal of Psychological Assessment, 11, 147-157. doi:10.1027/1015-5759.11.3.147

Hannan, T. E., Moffitt, R. L., Neumann, D. L., \& Thomas, P. R. (2015). Applying the theory of planned behavior physical activity: The moderating role of mental toughness. Journal of Sport \& Exercise Psychology, 37, 514-522. doi: 10.1123/jsep.2015-0074

Hardy, L., Bell, J., \& Beattie, S. (2014). A neuropsychological model of mentally tough behavior. Journal of Personality, 82, 69-81. doi:10.1111/jopy.12034

Healy, L. C., Ntoumanis, N., Veldhuijzen van Zanten, J. J. C. S., \& Paine, N. (2014). Goal striving and well-being in sport: The role of contextual and personal motivation. Journal of Sport \& Exercise Psychology, 36, 446-459. doi:10.1123/jsep.2013-0261

Hobfoll, S. E. (2002). Social and psychological resources and adaptation. Review of General Psychology, 6, 307-324.

Howle, T. C., Dimmock, J. A., \& Jackson, B. (2016). Relations between self-efficacy beliefs, self-presentation motives, personal task goals, and performance on endurance-based physical activity tasks. Psychology of Sport and Exercise, 22, 149-159. doi:10.1016/j.psychsport.2015.06.010

Jones, G., Hanton, S., \& Connaughton, D. (2002). What is this thing called mental toughness? An investigation of elite sport performers. Journal of Applied Sport Psychology, 14, 205-218. doi:10.1080/10413200290103509

Kuan, G., \& Roy, J. (2007). Gola profiles, mental toughness and its influence on performance outcomes among Wushu athletes. Journal of Sports Science and Medicine, 6, 28-33.

MacCallum, R. C., Roznowski, M., \& Necowitz, L. B. (1992). Model modifications in covariance structure analysis: The problem of capitalization on chance. Psychological Bulletin, 111, 490-504. doi:10.1037/0033-2909.111.3.490

Mahoney, J.W., Gucciardi, D.F., Ntoumanis, N., \& Mallett, C.J. (2014). Mental toughness in sport: Motivational antecedents and associations with performance and health. Journal of Sport \& Exercise Psychology, 36, 281-292. doi: 10.1123/jsep.2013-0260

Mahoney, J., Ntoumanis, N., Mallett, C., \& Gucciardi, D. (2014). The motivational antecedents of the development of mental toughness: A Self-Determination Theory perspective. International Review of Sport and Exercise Psychology, 1, 184-197. doi:10.1080/1750984X.2014.925951

Marsh, H. W., Muthén, B., Asparouhov, T., Lüdtke, O., Robitzsch, A., Morin, A. J. S., \& Trautwein, U. (2009). Exploratory structural equation modeling, integrating CFA and EFA: Application to students' evaluations of university teaching. Structural Equation Modeling, 16, 439-476. doi:10.1080/10705510903008220

McAdams, D. P., \& Pals, J. L. (2006). A new big five: Fundamental principles for an integrative science of personality. American Psychologist, 61, 204-217. doi:10.1037/0003-066X.61.3.204 
"Cross-Cultural Invariance of the Mental Toughness Inventory Among Australian, Chinese, and Malaysian Athletes: A Bayesian Estimation Approach" by Gucciardi DF et al.

Journal of Sport \& Exercise Psychology

(C) 2016 Human Kinetics, Inc.

McDonald, R. P. (1970). The theoretical foundations of principal factor analysis, canonical factor analysis and alpha factor analysis. British Journal of Mathematical Psychology, 23, 1-21. doi:10.1111/j.2044-8317.1970.tb00432.x

McDonald, R. P. (1999). Test theory: A unified treatment. Mahwah, NJ: Lawrence Erlbaum Associates.

Merriam, S. B., \& Mohamad, M. (2000). How cultural values shape learning in older adulthood: The case of Malaysia. Adult Education Quarterly, 51, 45-63. doi:10.1177/074171360005100104

Middleton, S. C., Marsh, H. W., Martin, A. J., Richards, G. E., Savis, J., Perry, C., \& Brown, R. (2004). The psychological performance inventory: Is the mental toughness test tough enough? International Journal of Sport Psychology, 35, 91-108.

Millsap, R. E. (2011). Statistical approaches to measurement invariance. New York, NY: Routledge.

Muthén, B., \& Asparouhov, T. (2012). Bayesian structural equation modeling: A more flexible representation of substantive theory. Psychological Methods, 17, 313-335. doi:10.1037/a0026802

Muthén, B., \& Asparouhov, T. (2013). BSEM measurement invariance analysis. Mplus Web Notes: No.17. https://www.statmodel.com/examples/webnotes/webnote17.pdf

Muthén, L. K., \& Muthén, B. O. (1998-2015). Mplus user's guide (7th ed.). Los Angeles, CA: Muthén \& Muthén.

Richman, W., Kiesler, S., Weisband, S., \& Drasgow, F. (1999). A meta-analytic study of social desirability distortion in computer-administered questionnaires, traditional questionnaires, and interviews. Journal of Applied Psychology, 84, 754 -775. doi: $10.1037 / 0021-9010.84 .5 .754$

Satorra, A., \& Bentler P. M. (2001). A scaled difference chi-square test statistic for moment structure analysis. Psychometrika, 66, 507-514. doi:10.1007/BF02296192

Si, G., Duan, Y., Li, H-Y., Zhang, C-Q., \& Su, N. (2015). The influence of the Chinese sport system and Chinese cultural characteristics on Olympic sport psychology services. Psychology of Sport and Exercise, 17, 56-67. doi: 10.1016/j.psychsport.2014.08.008

Stenling, A., Ivarsson, A., Johnson, U., \& Lindwall, M. (2015). Bayesian structural equation modeling in sport and exercise psychology. Journal of Sport \& Exercise Psychology, 37, 410-420. doi:10.1123/jsep.2014-0330

Triandis, H. C. (1995). Individualism and collectivism: New directions in social psychology. Boulder, CO: Westview Press.

Vandenberg, R. J., \& Lance, C. E. (2000). A review and synthesis of the measurement invariance literature: Suggestions, practices, and recommendations for organizational research. Organizational Research Methods, 3, 4-70. doi:10.1177/109442810031002

van de Schoot, R., Kluytmans, A., Tummers, L., Lugtig, P., Hox, J., \& Muthén, B. (2013). Facing off with Scylla and Charybdis: A comparison of scalar, partial and the novel 
"Cross-Cultural Invariance of the Mental Toughness Inventory Among Australian, Chinese, and Malaysian Athletes: A Bayesian Estimation Approach" by Gucciardi DF et al.

Journal of Sport \& Exercise Psychology

(C) 2016 Human Kinetics, Inc.

possibility of approximate measurement invariance. Frontiers in Psychology, 4: 770. doi:10.3389/fpsyg.2013.00770

van de Schoot, R., Kaplan, D., Denissen, J., Asendorpf, J. B., Neyer, F. J., \& Aken, M. A. (2014). A gentle introduction to Bayesian analysis: applications to developmental research. Child Development, 85, 842-860. doi:10.1111/cdev.12169

van De Schoot, R., Schmidt, P., De Beuckelaer, A., Lek, K., \& Zondervan-Zwijnenburg, M. (2015). Editorial: Measurement Invariance. Frontiers in Psychology, 6: 1024. doi:1064 10.3389/fpsyg.2015.01064

van de Vijver, F., \& Tanzer, N. K. (2004). Bias and equivalence in cross-cultural assessment: An overview. Revue Européenne de Psychologie AppliquéelEuropean Review of Applied Psychology, 54, 119-135. doi:10.1016/j.erap.2003.12.004

Xinyi, Z., Smith, D., \& Adegbola, O. (2004). A cross-cultural comparison of six mental qualities among Singaporean, North American, Chinese, and Nigerian professional athletes. International Journal of Sport and Exercise Psychology, 2, 103-118. doi:10.1080/1612197X.2004.9671735 
"Cross-Cultural Invariance of the Mental Toughness Inventory Among Australian, Chinese, and Malaysian Athletes: A Bayesian Estimation Approach" by Gucciardi DF et al. Journal of Sport \& Exercise Psychology

(c) 2016 Human Kinetics, Inc.

Table 1. Item-level statistics of the mental toughness inventory for Australian, Malaysian, and Chinese athletes.

\begin{tabular}{|c|c|c|c|c|c|c|c|c|c|c|c|c|}
\hline & \multicolumn{4}{|c|}{ Australian athletes $(n=353)$} & \multicolumn{4}{|c|}{ Malaysian athletes $(n=341)$} & \multicolumn{4}{|c|}{ Chinese athletes $(n=254)$} \\
\hline & $M$ & $S D$ & Skew & Kurtosis & $M$ & $S D$ & Skew & Kurtosis & $M$ & $S D$ & Skew & Kurtosis \\
\hline $\begin{array}{l}\text { I believe in my ability to achieve my } \\
\text { goals }\end{array}$ & 5.65 & 1.02 & -.89 & 1.12 & 6.02 & 1.11 & -1.10 & 1.38 & 5.60 & 1.17 & -.57 & -.17 \\
\hline $\begin{array}{l}\text { I am able to regulate my focus when } \\
\text { performing tasks }\end{array}$ & 5.46 & 1.04 & -1.01 & 1.96 & 5.59 & 1.22 & -1.26 & 2.38 & 5.47 & 1.14 & -.52 & .11 \\
\hline $\begin{array}{l}\text { I am able to use my emotions to perform } \\
\text { the way I want to }\end{array}$ & 5.18 & 1.25 & -.48 & -.18 & 5.76 & 1.28 & -1.26 & 1.95 & 5.38 & 1.12 & -.32 & -.43 \\
\hline I strive for continued success & 5.70 & 1.06 & -.81 & .71 & 6.25 & 1.06 & -1.97 & 5.21 & 5.77 & 1.11 & -.73 & .14 \\
\hline $\begin{array}{l}\text { I execute my knowledge of what is } \\
\text { required to achieve my goals }\end{array}$ & 5.62 & 1.02 & -.63 & .38 & 5.60 & 1.42 & -1.15 & 1.31 & 5.32 & 1.25 & -.61 & .01 \\
\hline I consistently overcome adversity & 5.34 & 1.14 & -.50 & .08 & 5.49 & 1.47 & -1.11 & 1.07 & 5.07 & 1.28 & -.66 & .57 \\
\hline $\begin{array}{l}\text { I am able execute appropriate skills or } \\
\text { knowledge when challenged }\end{array}$ & 5.71 & 1.14 & -.94 & -.99 & 5.75 & 1.25 & -1.14 & 1.71 & 5.16 & 1.22 & -.58 & .57 \\
\hline I can find a positive in most situations & 5.59 & 1.11 & -.60 & -.22 & 6.02 & 1.13 & -1.41 & 2.52 & 5.37 & 1.22 & -.52 & -.08 \\
\hline
\end{tabular}


"Cross-Cultural Invariance of the Mental Toughness Inventory Among Australian, Chinese, and Malaysian Athletes: A Bayesian Estimation Approach" by Gucciardi DF et al. Journal of Sport \& Exercise Psychology

(C) 2016 Human Kinetics, Inc.

Table 2. Standardized factor loadings $(\lambda)$, error terms $(\Theta)$, and latent factor reliability estimates of the mental toughness inventory for Australian, Malaysian, and Chinese athletes for the single-sample factor analyses with a Bayesian estimator (Bayes).

\begin{tabular}{|c|c|c|c|c|c|c|}
\hline & \multicolumn{2}{|c|}{$\begin{array}{l}\text { Australian athletes } \\
\qquad(n=353)\end{array}$} & \multicolumn{2}{|c|}{$\begin{array}{l}\text { Malaysian athletes } \\
\qquad(n=341)\end{array}$} & \multicolumn{2}{|c|}{$\begin{array}{c}\text { Chinese athletes } \\
\quad(n=254)\end{array}$} \\
\hline & $\lambda$ & $\theta$ & $\lambda$ & $\Theta$ & $\lambda$ & $\Theta$ \\
\hline I believe in my ability to achieve my goals & .63 & .61 & .56 & .69 & .63 & .60 \\
\hline I am able to regulate my focus when performing tasks & .68 & .55 & .64 & .59 & .73 & .47 \\
\hline I am able to use my emotions to perform the way I want to & .73 & .47 & .62 & .62 & .80 & .36 \\
\hline I strive for continued success & .64 & .59 & .66 & .57 & .72 & .48 \\
\hline I execute my knowledge of what is required to achieve my goals & .65 & .58 & .64 & .59 & .74 & .45 \\
\hline I consistently overcome adversity & .64 & .59 & .68 & .55 & .71 & .50 \\
\hline I am able execute appropriate skills or knowledge when challenged & .60 & .64 & .61 & .63 & .77 & .41 \\
\hline I can find a positive in most situations & .61 & .62 & .60 & .64 & .79 & .38 \\
\hline McDonald's omega $(\omega)$ coefficient & \multicolumn{2}{|c|}{.85} & \multicolumn{2}{|c|}{.84} & \multicolumn{2}{|c|}{.90} \\
\hline
\end{tabular}


"Cross-Cultural Invariance of the Mental Toughness Inventory Among Australian, Chinese, and Malaysian Athletes: A Bayesian Estimation Approach" by Gucciardi DF et al. Journal of Sport \& Exercise Psychology

(C) 2016 Human Kinetics, Inc.

Table 3. Standardized factor loadings $(\lambda)$ and item intercepts $(v)$ of the mental toughness inventory for Australian, Malaysian, and Chinese athletes for the configural invariance models with a Bayesian estimator.

\begin{tabular}{|c|c|c|c|c|c|c|}
\hline & \multicolumn{2}{|c|}{$\begin{array}{l}\text { Australian athletes } \\
\qquad(n=353)\end{array}$} & \multicolumn{2}{|c|}{$\begin{array}{l}\text { Malaysian athletes } \\
\qquad(n=341)\end{array}$} & \multicolumn{2}{|c|}{$\begin{array}{c}\text { Chinese athletes } \\
\qquad(n=254)\end{array}$} \\
\hline & $\lambda$ & $v$ & $\lambda$ & $v$ & $\lambda$ & $v$ \\
\hline I believe in my ability to achieve my goals & .63 & 5.66 & .57 & 6.02 & .64 & 5.61 \\
\hline I am able to regulate my focus when performing tasks & .68 & 5.46 & .65 & 5.59 & .73 & 5.48 \\
\hline I am able to use my emotions to perform the way I want to & .73 & 5.19 & .62 & 5.76 & .80 & 5.37 \\
\hline I strive for continued success & .63 & 5.70 & .67 & 6.25 & .72 & 5.77 \\
\hline I execute my knowledge of what is required to achieve my goals & .64 & 5.63 & .65 & 5.60 & .74 & 5.32 \\
\hline I consistently overcome adversity & .63 & 5.34 & .68 & 5.49 & .70 & 5.07 \\
\hline I am able execute appropriate skills or knowledge when challenged & .61 & 5.71 & .61 & 5.74 & .76 & 5.16 \\
\hline I can find a positive in most situations & .63 & 5.60 & .60 & 6.02 & .79 & 5.37 \\
\hline
\end{tabular}


"Cross-Cultural Invariance of the Mental Toughness Inventory Among Australian, Chinese, and Malaysian Athletes: A Bayesian Estimation Approach" by Gucciardi DF et al. Journal of Sport \& Exercise Psychology

(C) 2016 Human Kinetics, Inc.

Table 4. Standardized factor loadings $(\lambda)$ and item intercepts $(v)$ of the mental toughness inventory for Australian, Malaysian, and Chinese athletes for the metric invariance models with a Bayesian estimator.

\begin{tabular}{|c|c|c|c|c|c|c|}
\hline & \multicolumn{2}{|c|}{$\begin{array}{l}\text { Australian athletes } \\
\qquad(n=353)\end{array}$} & \multicolumn{2}{|c|}{$\begin{array}{c}\text { Malaysian athletes } \\
\qquad(n=341)\end{array}$} & \multicolumn{2}{|c|}{$\begin{array}{l}\text { Chinese athletes } \\
\qquad(n=254)\end{array}$} \\
\hline & $\lambda$ & $v$ & $\lambda$ & $v$ & $\lambda$ & $v$ \\
\hline I believe in my ability to achieve my goals & .67 & 5.66 & .64 & 6.02 & .63 & 5.61 \\
\hline I am able to regulate my focus when performing tasks & .74 & 5.46 & .67 & 5.59 & .75 & 5.48 \\
\hline I am able to use my emotions to perform the way I want to & .71 & 5.19 & .70 & 5.76 & .84 & 5.37 \\
\hline I strive for continued success & .69 & 5.70 & .72 & 6.25 & .71 & 5.77 \\
\hline I execute my knowledge of what is required to achieve my goals & .73 & 5.63 & .56 & 5.60 & .66 & 5.32 \\
\hline I consistently overcome adversity & .71 & 5.34 & .58 & 5.49 & .68 & 5.07 \\
\hline I am able execute appropriate skills or knowledge when challenged & .68 & 5.71 & .65 & 5.74 & .70 & 5.16 \\
\hline I can find a positive in most situations & .67 & 5.60 & .68 & 6.02 & .68 & 5.37 \\
\hline
\end{tabular}


"Cross-Cultural Invariance of the Mental Toughness Inventory Among Australian, Chinese, and Malaysian Athletes: A Bayesian Estimation Approach" by Gucciardi DF et al. Journal of Sport \& Exercise Psychology

(c) 2016 Human Kinetics, Inc.

Table 5. Standardized factor loadings $(\lambda)$ and item intercepts $(v)$ of the mental toughness inventory for Australian, Malaysian, and Chinese athletes for the scalar invariance models with a Bayesian estimator.

\begin{tabular}{|c|c|c|c|c|c|c|}
\hline & \multicolumn{2}{|c|}{$\begin{array}{l}\text { Australian athletes } \\
\qquad(n=353)\end{array}$} & \multicolumn{2}{|c|}{$\begin{array}{c}\text { Malaysian athletes } \\
\qquad(n=341)\end{array}$} & \multicolumn{2}{|c|}{$\begin{array}{l}\text { Chinese athletes } \\
\qquad(n=254)\end{array}$} \\
\hline & $\lambda$ & $v$ & $\lambda$ & $v$ & $\lambda$ & $v$ \\
\hline I believe in my ability to achieve my goals & .70 & 5.66 & .66 & 6.02 & .65 & 5.61 \\
\hline I am able to regulate my focus when performing tasks & .74 & 5.46 & .67 & 5.59 & .75 & 5.48 \\
\hline I am able to use my emotions to perform the way I want to & .71 & 5.19 & .71 & 5.76 & .86 & 5.37 \\
\hline I strive for continued success & .70 & 5.70 & .73 & 6.25 & .74 & 5.77 \\
\hline I execute my knowledge of what is required to achieve my goals & .73 & 5.63 & .56 & 5.60 & .64 & 5.32 \\
\hline I consistently overcome adversity & .70 & 5.34 & .57 & 5.49 & .66 & 5.07 \\
\hline I am able execute appropriate skills or knowledge when challenged & .68 & 5.71 & .65 & 5.74 & .66 & 5.16 \\
\hline I can find a positive in most situations & .68 & 5.60 & .68 & 6.02 & 67 & 5.37 \\
\hline
\end{tabular}


"Cross-Cultural Invariance of the Mental Toughness Inventory Among Australian, Chinese, and Malaysian Athletes: A Bayesian Estimation Approach" by Gucciardi DF et al. Journal of Sport \& Exercise Psychology

(C) 2016 Human Kinetics, Inc.

\section{Table 5 (Continued)}

\begin{tabular}{|c|c|c|c|c|c|c|c|c|c|c|c|c|}
\hline & \multicolumn{4}{|c|}{$\begin{array}{l}\text { Australian athletes } \\
\qquad(n=353)\end{array}$} & \multicolumn{4}{|c|}{$\begin{array}{l}\text { Malaysian athletes } \\
\qquad(n=341)\end{array}$} & \multicolumn{4}{|c|}{$\begin{array}{l}\text { Chinese athletes } \\
\qquad(n=254)\end{array}$} \\
\hline & $\lambda_{\mathrm{mlr}}$ & $v_{\mathrm{mlr}}$ & $\lambda_{\text {bayes }}$ & $v_{\text {bayes }}$ & $\lambda_{\mathrm{mlr}}$ & $v_{\mathrm{mlr}}$ & $\lambda_{\text {bayes }}$ & $v_{\text {bayes }}$ & $\lambda_{\mathrm{mlr}}$ & $v_{\mathrm{mlr}}$ & $\lambda_{\text {bayes }}$ & $v_{\text {bayes }}$ \\
\hline I believe in my ability to achieve my goals & 60 & 5.66 & .70 & 5.66 & .59 & 6.02 & .66 & 6.02 & .62 & 5.61 & .65 & 5.61 \\
\hline I am able to regulate my focus when performing tasks & .68 & 5.46 & .74 & 5.46 & .63 & 5.59 & .67 & 5.59 & .75 & 5.47 & .75 & 5.48 \\
\hline $\begin{array}{l}\text { I am able to use my emotions to perform the way I } \\
\text { want to }\end{array}$ & .63 & 5.19 & .71 & 5.19 & .63 & 5.76 & .71 & 5.76 & .83 & 5.36 & .86 & 5.37 \\
\hline I strive for continued success & .63 & 5.70 & .70 & 5.70 & .70 & 6.26 & .73 & 6.25 & .73 & 5.77 & .74 & 5.77 \\
\hline $\begin{array}{l}\text { I execute my knowledge of what is required to achieve } \\
\text { my goals }\end{array}$ & .66 & 5.63 & .73 & 5.63 & .52 & 5.60 & .56 & 5.60 & .68 & 5.32 & .64 & 5.32 \\
\hline I consistently overcome adversity & .60 & 5.34 & .70 & 5.34 & .51 & 5.49 & .57 & 5.49 & .65 & 5.07 & .66 & 5.07 \\
\hline $\begin{array}{l}\text { I am able execute appropriate skills or knowledge } \\
\text { when challenged }\end{array}$ & .58 & 5.70 & .68 & 5.71 & .59 & 5.75 & .65 & 5.74 & .71 & 5.16 & .66 & 5.16 \\
\hline I can find a positive in most situations & .59 & 5.60 & .68 & 5.60 & .63 & 6.02 & .68 & 6.02 & .72 & 5.37 & .67 & 5.37 \\
\hline
\end{tabular}


"Cross-Cultural Invariance of the Mental Toughness Inventory Among Australian, Chinese, and Malaysian Athletes: A Bayesian Estimation Approach" by Gucciardi DF et al. Journal of Sport \& Exercise Psychology

(C) 2016 Human Kinetics, Inc.

Table 6. Model-data fit indices for Bayesian estimation models.

\begin{tabular}{|c|c|c|c|c|c|c|c|}
\hline & \multirow[b]{2}{*}{$\# \mathrm{fp}$} & \multirow[b]{2}{*}{$\lambda$ prior } & \multirow[b]{2}{*}{$v$ prior } & \multicolumn{2}{|c|}{$\begin{array}{c}\text { Aobserved and } \\
\text { replicated } \chi^{2} 95 \% \text { CI }\end{array}$} & \multirow[b]{2}{*}{ PPP } & \multirow[b]{2}{*}{ DIC } \\
\hline & & & & $2.5 \% \mathrm{ppp}$ & $97.5 \% \mathrm{ppp}$ & & \\
\hline Configural & 156 & - & - & -44.67 & 45.96 & .493 & 21528 \\
\hline Metric (exact) & 140 & - & - & -40.76 & 49.38 & .423 & 21528 \\
\hline Metric (approx. MI) & 156 & .05 & - & -45.42 & 44.81 & .509 & 21526 \\
\hline Metric (approx. MI) & 156 & .01 & - & -43.93 & 45.85 & .488 & 21526 \\
\hline Metric (approx. MI) & 156 & .005 & - & -42.76 & 46.81 & .468 & 21527 \\
\hline Metric and scalar (exact) & 124 & - & - & 100.70 & 188.77 & .000 & 21654 \\
\hline Scalar (approx. MI) & 140 & - & .05 & -35.34 & 55.74 & .323 & 21532 \\
\hline Scalar (approx. MI) & 140 & - & .01 & -9.97 & 83.77 & .061 & 21555 \\
\hline Scalar (approx. MI) & 140 & - & .005 & 10.68 & 105.16 & .009 & 21573 \\
\hline Metric and scalar (approx. MI) & 156 & .05 & .05 & -39.79 & 51.67 & .403 & 21530 \\
\hline Metric and scalar (approx. MI) & 156 & .01 & .01 & -13.29 & 80.10 & .081 & 21552 \\
\hline Metric and scalar (approx. MI) & 156 & .005 & .005 & 8.79 & 102.86 & .011 & 21571 \\
\hline Metric and scalar (partial) & 133 & - & - & -34.786 & 54.28 & .329 & 21527 \\
\hline
\end{tabular}

Note: $\# \mathrm{fp}=$ number of free parameters; $\lambda=$ factor loading prior variance of difference between groups; $v=$ item intercept prior variance of difference between groups; $\mathrm{CI}=$ credibility interval; $\mathrm{PPP}=$ posterior predictive $\mathrm{p}$ value; $\mathrm{DIC}=$ deviance information criterion; Metric and scalar $($ partial $)=$ invariant parameters are held exactly equal, whereas non-invariant parameters are freely estimated (i.e., intercepts of items $1,3,4,7$ and 8 for Malaysian athletes; and 5, 6, 7, and 8 for Chinese athletes). 
"Cross-Cultural Invariance of the Mental Toughness Inventory Among Australian, Chinese, and Malaysian Athletes: A Bayesian Estimation Approach" by Gucciardi DF et al.

Journal of Sport \& Exercise Psychology

(C) 2016 Human Kinetics, Inc.

Table 7. Difference output from approximate measurement invariance with Bayesian estimation with priors for factor loadings and intercepts that are close to zero $\left(\mu=0, \sigma^{2}=\right.$ $.05)$.

\begin{tabular}{|c|c|c|c|c|c|}
\hline & \multirow{2}{*}{\multicolumn{2}{|c|}{$\begin{array}{c}\text { Parameter } \\
\text { Value }\end{array}$}} & \multirow{2}{*}{\multicolumn{3}{|c|}{ Deviations from Mean }} \\
\hline & & & & & \\
\hline & Mean & SD & Australian & Malaysian & Chinese \\
\hline Factor loading (item 1) & .69 & .07 & -.03 & -.01 & .05 \\
\hline Factor loading (item 2) & .80 & .06 & -.06 & .03 & .03 \\
\hline Factor loading (item 3) & .88 & .07 & .02 & -.03 & .02 \\
\hline Factor loading (item 4) & .74 & .06 & -.04 & .00 & .04 \\
\hline Factor loading (item 5) & .82 & .07 & -.12 & .05 & .08 \\
\hline Factor loading (item 6) & .86 & .08 & -.08 & .05 & .03 \\
\hline Factor loading (item 7) & .82 & .07 & -.08 & .00 & .07 \\
\hline Factor loading (item 8) & .79 & .07 & -.07 & -.05 & .12 \\
\hline Intercept (item 1) & 5.77 & .04 & $-.09 *$ & $.17 *$ & -.08 \\
\hline Intercept (item 2) & 5.52 & .04 & -.04 & .00 & .04 \\
\hline Intercept (item 3) & 5.45 & .04 & $-.22 *$ & $.21^{*}$ & .01 \\
\hline Intercept (item 4) & 5.92 & .04 & $-.18 *$ & $.25^{*}$ & -.06 \\
\hline Intercept (item 5) & 5.53 & .04 & $.11^{*}$ & .00 & $-.10 *$ \\
\hline Intercept (item 6) & 5.31 & .04 & .04 & .09 & $-.13 *$ \\
\hline Intercept (item 7) & 5.55 & .04 & $.16^{*}$ & $.11^{*}$ & $-.26^{*}$ \\
\hline Intercept (item 8) & 5.68 & .04 & -.06 & $.25^{*}$ & $-.19 *$ \\
\hline
\end{tabular}


"Cross-Cultural Invariance of the Mental Toughness Inventory Among Australian, Chinese, and Malaysian Athletes: A Bayesian Estimation Approach" by Gucciardi DF et al.

Journal of Sport \& Exercise Psychology

(C) 2016 Human Kinetics, Inc.

\section{Appendix A - Overview and Results of the Traditional Frequentist Approach to}

\section{Measurement Invariance}

As a supplement to the Bayesian analyses presented in the main document, we also performed measurement invariance analyses using a traditional exact approach with a robust maximum likelihood estimator (MLR). In contrast to the Bayesian approach, residual covariances were specified as uncorrelated and therefore forced to be zero in this frequentist approach to measurement invariance. Model-data fit was assessed using established indices, namely the $\chi^{2}$ goodness-of-fit index, comparative fit index (CFI), Tucker-Lewis index (TLI), and root mean square error of approximation (RMSEA). According to typical interpretation guidelines for adequate or acceptable model-data fit (e.g., Browne \& Cudeck, 1993; Hu \& Bentler, 1998; Marsh, Hau, \& Grayson, 2005; Marsh, Hau, \& Wen, 2004; Tabachnick \& Fidell, 2007), values of CFI/TLI $\geq .90$ and RMSEA $\leq .06$ (with the upper bound of the $90 \%$ RMSEA confidence interval $\leq .10$ ) provide evidence of adequate or acceptable overall fit. Nevertheless, it is important to acknowledge that these values represent guidelines rather than 'golden rule's (i.e., yes/no decision). With regard to exact measurement invariance analyses with the frequentist approach, scaled $\chi^{2}$ difference tests were corrected for non-normality between

nested models because we utilized the MLR estimator (Satorra \& Bentler, 2001). As $\chi^{2}$ difference tests can be sensitive to sample size (Tabachnick \& Fidell, 2007), we also considered two additional recommendations for support of invariance between two competing models, namely a change in CFI of less than .01 (Cheung \& Rensvold, 2002), and a change in RMSEA of less than .015 (Chen, 2007).

\section{Factorial Validation of the MTI}

Analyses indicated that the 8-item unidimensional model was a good fit with the data in the Australian, $\chi^{2}(20)=39.41, p=.006, \mathrm{CFI}=.965, \mathrm{TLI}=.951, \mathrm{RMSEA}=.052(90 \% \mathrm{CI}=$ 
"Cross-Cultural Invariance of the Mental Toughness Inventory Among Australian, Chinese, and Malaysian Athletes: A Bayesian Estimation Approach" by Gucciardi DF et al.

Journal of Sport \& Exercise Psychology

(c) 2016 Human Kinetics, Inc.

.027 to .076$)$ and Malaysian athletes, $\chi^{2}(20)=35.50, p=.02, \mathrm{CFI}=.944, \mathrm{TLI}=.922$, RMSEA $=.048(90 \% \mathrm{CI}=.020$ to .073$)$; however, model-data fit was inadequate with the Chinese athletes, $\chi^{2}(20)=80.77, p<.001, \mathrm{CFI}=.916, \mathrm{TLI}=.882, \mathrm{RMSEA}=.109(90 \% \mathrm{CI}=.085$ to .135). Modification indices revealed that model-data fit could be improved by modeling several residual covariances among the mental toughness items; because this issue is dealt in an a priori manner with Bayesian estimation, we decided not to make these post hoc modifications within the frequentist approach. Across all three samples, factor loadings and latent factor reliability estimates were excellent (see Table 2).

\section{Cross-Cultural Invariance of the MTI}

Analyses provided support for model-data fit with the configural, $\chi^{2}(60)=144.57, p<$ $.001, \mathrm{CFI}=.940, \mathrm{TLI}=.916, \mathrm{RMSEA}=.067(90 \% \mathrm{CI}=.053$ to .081$)$, and metric models, $\chi^{2}$ $(74)=156.37, p<.001, \mathrm{CFI}=.941, \mathrm{TLI}=.933, \mathrm{RMSEA}=.059(90 \% \mathrm{CI}=.046$ to .072$)$, but not the scalar model, $\chi^{2}(88)=253.30, p<.001, \mathrm{CFI}=.882, \mathrm{TLI}=.888, \mathrm{RMSEA}=.077(90 \%$ $\mathrm{CI}=.066$ to .088$)$. Model comparisons revealed that the difference between the metric model and the configural model was not statistically significant, $\Delta \chi^{2}(14)=8.55, p=.86, \Delta \mathrm{CFI}=.001$, $\triangle \mathrm{RMSEA}=.008$ thus supporting invariance of factor loadings. However, the difference between the scalar model and the metric model was statistically significant, $\Delta \chi^{2}(14)=130.63$, $p<.001, \Delta \mathrm{CFI}=.059, \Delta \mathrm{RMSEA}=.018$, thereby failing to support the invariance of item intercepts. In cases where a specific level of invariance is not supported (e.g., scalar invariance), researchers can explore partial invariance by releasing equality constraints of parameters where there is a large difference between groups (Byrne, Shavelson, \& Muthén 1989). Accordingly, we released the constraints of the intercepts of items 1, 3, 4, 7, and 8 and found support for this model of partial scalar invariance, $\chi^{2}(78)=170.31, p<.001, \mathrm{CFI}=.934$, $\mathrm{TLI}=.929, \mathrm{RMSEA}=.061(90 \% \mathrm{CI}=.049$ to .074$)$. Model comparisons revealed that the 
"Cross-Cultural Invariance of the Mental Toughness Inventory Among Australian, Chinese, and Malaysian Athletes: A Bayesian Estimation Approach" by Gucciardi DF et al.

Journal of Sport \& Exercise Psychology

(C) 2016 Human Kinetics, Inc.

difference between the metric model and the partial scalar invariance model was not statistically significant, $\Delta \chi^{2}(4)=13.94, p<.001, \Delta \mathrm{CFI}=.007, \Delta \mathrm{RMSEA}=.002$. Across all three samples and levels of measurement invariance, factor loadings were excellent (see Tables 3,4 , and 5).

\section{Discussion}

With the exact approach to measurement invariance, we found that item scores do not have the same scaling across the three cultural groups. An inspection of item-level descriptive statistics indicated that Malaysian athletes typically provided higher means than both the Australian and Chinese participants, whereas Australian athletes generally reported higher means than the Chinese participants. Because there is evidence that some of the items are not invariant across the three cultural groups, the comparison of composite or observed means of mental toughness between these groups is not advisable (Cheung \& Rensvold, 2002; Vandenberg \& Lance, 2000) 
"Cross-Cultural Invariance of the Mental Toughness Inventory Among Australian, Chinese, and Malaysian Athletes: A Bayesian Estimation Approach" by Gucciardi DF et al. Journal of Sport \& Exercise Psychology

(C) 2016 Human Kinetics, Inc.

Table 2. Standardized factor loadings $(\lambda)$, error terms $(\Theta)$, and latent factor reliability estimates of the mental toughness inventory for Australian, Malaysian, and Chinese athletes for the single-sample factor analyses with a robust maximum likelihood estimator.

\begin{tabular}{|c|c|c|c|c|c|c|}
\hline & \multicolumn{2}{|c|}{$\begin{array}{c}\text { Australian athletes } \\
\qquad(n=353)\end{array}$} & \multicolumn{2}{|c|}{$\begin{array}{l}\text { Malaysian athletes } \\
\qquad(n=341)\end{array}$} & \multicolumn{2}{|c|}{$\begin{array}{c}\text { Chinese athletes } \\
\quad(n=254)\end{array}$} \\
\hline & $\lambda$ & $\theta$ & $\lambda$ & $\Theta$ & $\lambda$ & $\Theta$ \\
\hline I believe in my ability to achieve my goals & .62 & .62 & .58 & .67 & .60 & .64 \\
\hline I am able to regulate my focus when performing tasks & .68 & .54 & .65 & .57 & .73 & .47 \\
\hline I am able to use my emotions to perform the way I want to & 67 & .55 & .61 & .63 & .82 & .33 \\
\hline I strive for continued success & .63 & .60 & .72 & .48 & .71 & .50 \\
\hline I execute my knowledge of what is required to achieve my goals & .65 & .58 & .53 & .72 & .69 & .53 \\
\hline I consistently overcome adversity & .59 & .65 & .54 & .71 & .64 & .59 \\
\hline I am able execute appropriate skills or knowledge when challenged & .55 & .69 & .58 & .67 & .74 & .45 \\
\hline I can find a positive in most situations & .56 & .69 & .60 & .65 & .76 & .42 \\
\hline McDonald's omega $(\omega)$ coefficient & \multicolumn{2}{|c|}{.83} & \multicolumn{2}{|c|}{.82} & \multicolumn{2}{|c|}{.89} \\
\hline
\end{tabular}


"Cross-Cultural Invariance of the Mental Toughness Inventory Among Australian, Chinese, and Malaysian Athletes: A Bayesian Estimation Approach" by Gucciardi DF et al. Journal of Sport \& Exercise Psychology

(C) 2016 Human Kinetics, Inc.

Table 3. Standardized factor loadings $(\lambda)$ and item intercepts $(v)$ of the mental toughness inventory for Australian, Malaysian, and Chinese athletes for the configural invariance models with a robust maximum likelihood estimator.

\begin{tabular}{|c|c|c|c|c|c|c|}
\hline & \multicolumn{2}{|c|}{$\begin{array}{l}\text { Australian athletes } \\
\qquad(n=353)\end{array}$} & \multicolumn{2}{|c|}{$\begin{array}{c}\text { Malaysian athletes } \\
\qquad(n=341)\end{array}$} & \multicolumn{2}{|c|}{$\begin{array}{l}\text { Chinese athlete } \\
\qquad(n=254)\end{array}$} \\
\hline & $\lambda$ & $v$ & $\lambda$ & $v$ & $\lambda$ & $v$ \\
\hline I believe in my ability to achieve my goals & .62 & 5.66 & .58 & 6.02 & .60 & 5.61 \\
\hline I am able to regulate my focus when performing tasks & .68 & 5.46 & .65 & 5.59 & .73 & 5.47 \\
\hline I am able to use my emotions to perform the way I want to & .67 & 5.19 & .61 & 5.76 & .82 & 5.36 \\
\hline I strive for continued success & .63 & 5.70 & .72 & 6.26 & .71 & 5.77 \\
\hline I execute my knowledge of what is required to achieve my goals & .65 & 5.63 & .53 & 5.60 & 69 & 5.32 \\
\hline I consistently overcome adversity & .59 & 5.34 & .54 & 5.49 & .64 & 5.07 \\
\hline I am able execute appropriate skills or knowledge when challenged & .55 & 5.70 & .58 & 5.75 & .74 & 5.16 \\
\hline I can find a positive in most situations & .56 & 5.60 & .60 & 6.02 & .76 & 5.37 \\
\hline
\end{tabular}


"Cross-Cultural Invariance of the Mental Toughness Inventory Among Australian, Chinese, and Malaysian Athletes: A Bayesian Estimation Approach" by Gucciardi DF et al. Journal of Sport \& Exercise Psychology

(C) 2016 Human Kinetics, Inc.

Table 4. Standardized factor loadings $(\lambda)$ and item intercepts $(v)$ of the mental toughness inventory for Australian, Malaysian, and Chinese athletes for the metric invariance models with a robust maximum likelihood estimator.

\begin{tabular}{|c|c|c|c|c|c|c|}
\hline & \multicolumn{2}{|c|}{$\begin{array}{c}\text { Australian athletes } \\
\qquad(n=353)\end{array}$} & \multicolumn{2}{|c|}{$\begin{array}{c}\text { Malaysian athletes } \\
\qquad(n=341)\end{array}$} & \multicolumn{2}{|c|}{$\begin{array}{l}\text { Chinese athletes } \\
\qquad(n=254)\end{array}$} \\
\hline & $\lambda$ & $v$ & $\lambda$ & $v$ & $\lambda$ & $v$ \\
\hline I believe in my ability to achieve my goals & .60 & 5.66 & .59 & 6.02 & .62 & 5.61 \\
\hline I am able to regulate my focus when performing tasks & .68 & 5.46 & .63 & 5.59 & .75 & 5.47 \\
\hline I am able to use my emotions to perform the way I want to & .63 & 5.19 & .63 & 5.76 & .83 & 5.36 \\
\hline I strive for continued success & .63 & 5.70 & .70 & 6.26 & .73 & 5.77 \\
\hline I execute my knowledge of what is required to achieve my goals & .66 & 5.63 & .52 & 5.60 & .68 & 5.32 \\
\hline I consistently overcome adversity & .60 & 5.34 & .51 & 5.49 & 65 & 5.07 \\
\hline I am able execute appropriate skills or knowledge when challenged & .58 & 5.70 & .59 & 5.75 & .71 & 5.16 \\
\hline I can find a positive in most situations & .59 & 5.60 & .63 & 6.02 & .72 & 5.37 \\
\hline
\end{tabular}


"Cross-Cultural Invariance of the Mental Toughness Inventory Among Australian, Chinese, and Malaysian Athletes: A Bayesian Estimation Approach" by Gucciardi DF et al. Journal of Sport \& Exercise Psychology

(C) 2016 Human Kinetics, Inc.

Table 5. Standardized factor loadings $(\lambda)$ and item intercepts $(v)$ of the mental toughness inventory for Australian, Malaysian, and Chinese athletes for the scalar invariance models with a robust maximum likelihood estimator.

\begin{tabular}{|c|c|c|c|c|c|c|}
\hline & \multicolumn{2}{|c|}{$\begin{array}{c}\text { Australian athletes } \\
\qquad(n=353)\end{array}$} & \multicolumn{2}{|c|}{$\begin{array}{c}\text { Malaysian athletes } \\
\qquad(n=341)\end{array}$} & \multicolumn{2}{|c|}{$\begin{array}{l}\text { Chinese athletes } \\
\qquad(n=254)\end{array}$} \\
\hline & $\lambda$ & $v$ & $\lambda$ & $v$ & $\lambda$ & $v$ \\
\hline I believe in my ability to achieve my goals & .60 & 5.66 & .59 & 6.02 & .62 & 5.61 \\
\hline I am able to regulate my focus when performing tasks & .68 & 5.46 & .63 & 5.59 & .75 & 5.47 \\
\hline I am able to use my emotions to perform the way I want to & .63 & 5.19 & .63 & 5.76 & .83 & 5.36 \\
\hline I strive for continued success & .63 & 5.70 & .70 & 6.26 & .73 & 5.77 \\
\hline I execute my knowledge of what is required to achieve my goals & .66 & 5.63 & .52 & 5.60 & .68 & 5.32 \\
\hline I consistently overcome adversity & .60 & 5.34 & .51 & 5.49 & 65 & 5.07 \\
\hline I am able execute appropriate skills or knowledge when challenged & .58 & 5.70 & .59 & 5.75 & .71 & 5.16 \\
\hline I can find a positive in most situations & .59 & 5.60 & .63 & 6.02 & .72 & 5.37 \\
\hline
\end{tabular}


"Cross-Cultural Invariance of the Mental Toughness Inventory Among Australian, Chinese, and Malaysian Athletes: A Bayesian Estimation Approach" by Gucciardi DF et al.

Journal of Sport \& Exercise Psychology

(C) 2016 Human Kinetics, Inc.

\section{References}

Browne, M.W., \& Cudeck, R. (1993). Alternative ways of assessing model fit. In K. A. Bollen, \& J.S. Long (Eds.), Testing structural equation models (pp. 136-162). Newbury Park, CA: Sage.

Byrne, B. M., Shavelson, R. J., \& Muthén, B. (1989). Testing for the equivalence of factor covariance and mean structures: The issue of partial measurement invariance. Psychological Bulletin, 105, 456-466.

Chen, F. F. (2007). Sensitivity of goodness of fit indices to lack of measurement invariance. Structural Equation Modeling, 14, 464-504. doi:10.1080/10705510701301834

Cheung, G. W., \& Rensvold, R. B. (2002). Evaluating goodness-of-fit indexes for testing measurement invariance. Structural Equation Modeling, 9, 233-255. doi:10.1207/S15328007SEM0902_5.

Hu, L.-T., \& Bentler, P.M. (1998). Fit indices in covariance structure modeling: Sensitivity to underparameterized model misspecification. Psychological Methods, 3, 424-453.

Marsh, H. W., Hau, K.-T., \& Grayson, D. (2005). Goodness of fit evaluation in structural equation modeling. In A. Maydeu-Olivares \& J. McArdle (Eds.), Psychometrics. A Festschrift for Roderick P. McDonald (pp. 275-340). Hillsdale, NJ: Erlbaum.

Marsh, H.W., Hau, K.-T., \& Wen, Z. (2004). In search of golden rules: Comment on hypothesis-testing approaches to cutoff values for fit indexes and dangers in overgeneralizing Hu \& Bentler's (1999). Structural Equation Modeling, 11, 320-341.

Satorra, A., \& Bentler P. M. (2001). A scaled difference chi-square test statistic for moment structure analysis. Psychometrika, 66, 507-514. doi:10.1007/BF02296192

Tabachnick, B. S., \& Fidell, L. S. (2007). Using multivariate statistics (5th ed.). Boston, MA: Allyn and Bacon.

Vandenberg, R. J., \& Lance, C. E. (2000). A review and synthesis of the measurement invariance literature: Suggestions, practices, and recommendations for organizational research. Organizational Research Methods, 3, 4-70. doi:10.1177/109442810031002 
"Cross-Cultural Invariance of the Mental Toughness Inventory Among Australian, Chinese, and Malaysian Athletes: A Bayesian Estimation Approach" by Gucciardi DF et al.

Journal of Sport \& Exercise Psychology

(C) 2016 Human Kinetics, Inc.

Table S1. Malay version of the 8-item Mental Toughness Inventory.

ARAHAN : Menggunakan skala di bawah, sila nyatakan betapa benarnya setiap kenyataan berikut yang menunjukkan bagaimana cara biasa anda berfikir, rasa dan bertindak sebagai pemain bola jaring - sila ambil ambil maklum bawa tiada jawapan yang betul atau salah, oleh itu buat dengan sejujurnya.

\begin{tabular}{|c|c|ccccc|}
\hline 1 & 2 & 3 & 4 & 5 & 6 & 7 \\
$\begin{array}{c}\text { Palsu, 100\% tidak } \\
\text { benar pada setiap } \\
\text { masa }\end{array}$ & & & & & & $\begin{array}{c}\text { Benar, 100\% benar } \\
\text { pada setiap masa }\end{array}$ \\
\hline
\end{tabular}

\begin{tabular}{|c|c|c|c|c|c|c|c|}
\hline $\begin{array}{l}\text { Saya yakin dengan keupayaan saya untuk mencapai } \\
\text { matlamat saya }\end{array}$ & 1 & 2 & 3 & 4 & 5 & 6 & 7 \\
\hline $\begin{array}{l}\text { Saya dapat menyelaraskan tumpuan saya ketika } \\
\text { melakukan tugasan }\end{array}$ & 1 & 2 & 3 & 4 & 5 & 6 & 7 \\
\hline Saya mampu bangkit dari kesusahan yang dialami & 1 & 2 & 3 & 4 & 5 & 6 & 7 \\
\hline Saya berusaha gigih untuk kejayaan yang berterusan & 1 & 2 & 3 & 4 & 5 & 6 & 7 \\
\hline $\begin{array}{l}\text { Saya dapat melihat sesuatu yang positif dalam kebanyakan } \\
\text { situasi }\end{array}$ & 1 & 2 & 3 & 4 & 5 & 6 & t \\
\hline $\begin{array}{l}\text { Saya dapat menggunakan emosi saya untuk capai prestasi } \\
\text { yang saya inginkan }\end{array}$ & 1 & 2 & 3 & 4 & 5 & 6 & 7 \\
\hline $\begin{array}{l}\text { Saya mampu mengekalkan tahap terbaik prestasi apabila } \\
\text { dicabar }\end{array}$ & 1 & 2 & 3 & 4 & 5 & 6 & 7 \\
\hline $\begin{array}{l}\text { Saya menggunakan pengetahuan saya dengan berkesan } \\
\text { untuk mencapai matlamat saya }\end{array}$ & 1 & 2 & 3 & 4 & 5 & 6 & I \\
\hline
\end{tabular}


"Cross-Cultural Invariance of the Mental Toughness Inventory Among Australian, Chinese, and Malaysian Athletes: A Bayesian Estimation Approach" by Gucciardi DF et al.

Journal of Sport \& Exercise Psychology

(C) 2016 Human Kinetics, Inc.

Table S2. Chinese version of the 8-item Mental Toughness Inventory.

\section{心理堅韎性指標}

指導語：使用下述標準, 請指出你對下述句子代表你作為一名運動員如何進行思考、

感覺和行動的同意程度。記住答案沒有對錯，因此請盡可能誠實地回答。

\begin{tabular}{|c|c|c|c|c|c|c|}
\hline 1 & 2 & 3 & 4 & 5 & 6 & 7 \\
\hline $100 \%$ 的時候 & & & & & & $100 \%$ 的時候 \\
\hline 不符合 & & & & & & 符合 \\
\hline
\end{tabular}

1. 我相信自己有實現目標的能力。

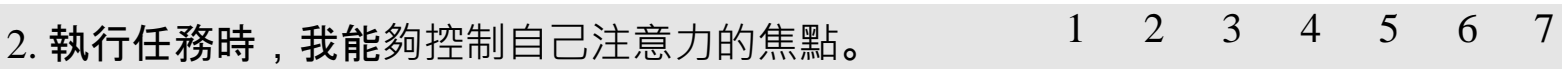

3. 我努力、堅持地克服逆境。

$\begin{array}{lllllll}1 & 2 & 3 & 4 & 5 & 6 & 7\end{array}$

4. 我為每一次的成功而奮鬥。 $\begin{array}{lllllll}1 & 2 & 3 & 4 & 5 & 6 & 7\end{array}$

5. 在多數情形下, 我都能找到積極的一面。

$\begin{array}{lllllll}1 & 2 & 3 & 4 & 5 & 6 & 7\end{array}$

6. 我能夠掌握情緒以自己想要的方式來表現。

$\begin{array}{lllllll}1 & 2 & 3 & 4 & 5 & 6 & 7\end{array}$

7. 遇到挑戰時，我能夠運用恰當的技能或知識。

$\begin{array}{lllllll}1 & 2 & 3 & 4 & 5 & 6 & 7\end{array}$

8. 我有效地運用自己所需的知識與技能來實現目標。

$\begin{array}{lllllll}1 & 2 & 3 & 4 & 5 & 6 & 7\end{array}$


"Cross-Cultural Invariance of the Mental Toughness Inventory Among Australian, Chinese, and Malaysian Athletes: A Bayesian Estimation Approach" by Gucciardi DF et al.

Journal of Sport \& Exercise Psychology

(C) 2016 Human Kinetics, Inc.

Table S3. Mplus syntax for single-sample factor analysis of unidimensional mental toughness inventory with Bayesian estimation. (Note: code preceded by an exclamation mark is not read by Mplus when the run is executed).

TITLE: Cross-cultural invariance analyses of the MTI - baseline model

DATA: ! informs Mplus which file to use in the analysis

FILE = Australian data.csv;

! FILE = Malaysian data.csv;

! FILE = Chinese data.csv;

VARIABLE: NAMES = country mti1 mti2 mti3 mti4 mti5 mti6 mti7 mti8;

USEVARIABLES = mti1 mti2 mti3 mti4 mti5 mti6 mti7 mti8;

MISSING = ALL (999); ! informs Mplus which responses are missing

MODEL:

MT BY mti1* mti2 mti3 mti4 mti5 mti6 mti7 mti8; !* used to freely estimate first loading MT@1; ! fix the factor variance to 1

mti1-mti8 (rv1-rv8); ! freely estimate residual variances (provides a name for each( mti1-mti8 WITH mti1-mti8 (cr1-cr28); ! freely estimate residual covariances (provides a

! name for each)

ANALYSIS:

ESTIMATOR = BAYES; ! Bayesian estimation using a Markov chain Monte Carlo (MCMC) ! algorithm (see pp. 608-609 of the user guide)

PROCESSOR $=4$; ! when multiple processors are available, computation can be speeded up ! by specifying the number of processors available for parallel computing, with one chain per ! processor (see pp. 648-650 of the user guide)

CHAINS $=4 ;$ ! specifies 4 independent MCMC chains to be employed in the analysis

! (see p. 642 of the user guide)

FBITERATIONS $=150000 ;$ ! specifies a fixed number of iterations for MCMC estimation

! (see p. 645 of the user guide)

MODEL PRIORS:

rv1-rv8 IW $(1,15)$; ! priors for residual variances modeled with inverse-Wishart

distribution

cr1-cr28 IW $(0,15)$; ! priors residual covariances modeled with inverse-Wishart

distribution

OUTPUT: STDYX CINTERVAL(HPD) TECH1 TECH8;

! (see pp. 736-757 of the user guide) 
"Cross-Cultural Invariance of the Mental Toughness Inventory Among Australian, Chinese, and Malaysian Athletes: A Bayesian Estimation Approach" by Gucciardi DF et al.

Journal of Sport \& Exercise Psychology

(c) 2016 Human Kinetics, Inc.

Table S4. Mplus syntax for single-sample factor analysis of unidimensional mental toughness inventory with robust maximum likelihood estimator. (Note: code preceded by an exclamation mark is not read by Mplus when the run is executed).

TITLE: Cross-cultural invariance analyses of the MTI - baseline model DATA:

FILE $=$ Australian data.csv;

! FILE = Malaysian data.csv;

! FILE = Chinese data.csv;

VARIABLE: NAMES = country mti1 mti2 mti3 mti4 mti5 mti6 mti7 mti8;

USEVARIABLES = mti1 mti2 mti3 mti4 mti5 mti6 mti7 mti8;

MISSING = ALL (999);

MODEL:

MT BY mti1* mti2 mti3 mti4 mti5 mti6 mti7 mti8;

MT@1;

ANALYSIS:

ESTIMATOR = MLR; ! robust maximum likelihood estimator (see pp. 605-608 of the user ! guide) 
"Cross-Cultural Invariance of the Mental Toughness Inventory Among Australian, Chinese, and Malaysian Athletes: A Bayesian Estimation Approach" by Gucciardi DF et al.

Journal of Sport \& Exercise Psychology

(c) 2016 Human Kinetics, Inc.

Table S5. Mplus syntax for exact zero invariance analysis of unidimensional mental toughness inventory with robust maximum likelihood estimator. (Note: code preceded by an exclamation mark is not read by Mplus when the run is executed).

TITLE: Cross-cultural invariance analyses of the MTI - exact zero invariance test DATA:

FILE = Combined data.csv; ! data for each country have been combined in a single file

VARIABLE: NAMES = country mti1 mti2 mti3 mti4 mti5 mti6 mti7 mti8;

GROUPING $=$ country $(0=$ aus, $1=$ mal, $2=$ chi $) !$ informs Mplus which variable contains ! group membership information when data is stored in single data file

USEVARIABLES = mti $1 \mathrm{mti} 2 \mathrm{mti} 3 \mathrm{mti} 4 \mathrm{mti} 5 \mathrm{mti} 6 \mathrm{mti} 7 \mathrm{mti} 8$;

MISSING = ALL (999);

MODEL:

MT BY mti1 mti2 mti3 mti4 mti5 mti6 mti7 mti8; ! unlike the previous examples, here the ! first factor loading is fixed to 1 to set the metric of the factor (i.e., default in Mplus)

ANALYSIS:

ESTIMATOR = MLR;

MODEL = CONFIGURAL METRIC SCALAR; ! informs Mplus to estimate these models ! using the multi-group convenience feature of Mplus. One can specify each of these levels of ! invariance in isolation (e.g., MODEL = METRIC;)

OUTPUT: STDYX SAMPSTAT; 
"Cross-Cultural Invariance of the Mental Toughness Inventory Among Australian, Chinese, and Malaysian Athletes: A Bayesian Estimation Approach" by Gucciardi DF et al.

Journal of Sport \& Exercise Psychology

(C) 2016 Human Kinetics, Inc.

Table S6. Mplus syntax for exact zero configural invariance analysis of unidimensional mental toughness inventory with Bayesian estimation. (Note: code preceded by an exclamation mark is not read by Mplus when the run is executed).

TITLE: Cross-cultural invariance analyses of the MTI - exact configural invariance with Bayesian estimation ! see example 5.33 of the user guide

DATA: FILE = Combined data.csv; ! data for each country have been combined in a single file

VARIABLE: NAMES = country mti1 mti2 mti3 mti4 mti5 mti6 mti7 mti8;

KNOWNCLASS IS g(country=0 country=1 country=2); ! In Mplus, Bayesian multi-group ! analysis requires the CLASSES and KNOWNCLASS options and TYPE=MIXTURE.

CLASSES IS g(3);

USEVARIABLES = mti1 mti2 mti3 mti4 mti5 mti6 mti7 mti8;

MISSING = ALL (999);

MODEL:

\%overall\% ! part of the model common to all classes, which is known groups in this instance MT BY mti1* mti2 mti3 mti4 mti5 mti6 mti7 mti8 (fl\#_1-fl\#_8); ! no constraints on factor ! loadings across groups (provides a name for each; e.g., fl\#_ 1 is assigned to the factor loading ! for item 1)

MT@1;

[MT@0];

[mti1-mti8*] (nu\#_1-nu\#_8); ! no constraints on item intercepts (provides a name for each) mti1-mti8 (rv\#_1-rv\#_8); ! no constraints on residual variances (provides a name for each) mti1-mti8 WITH mti1-mti8 (cr\#_1-cr\#_28); ! no constraints on residual covariances (provides ! a name for each) (see p. 612 of the user guide for naming details when using TYPE=mixture)

ANALYSIS:

MODEL = allfree; ! frees parameters for TYPE=MIXTURE (pp. 611-612 of the user guide) TYPE = mixture; ! Bayesian invariance is executed using mixture modeling in Mplus

ESTIMATOR $=$ BAYES;

PROCESSOR $=4$;

CHAINS $=4$;

FBITERATIONS $=150000$;

MODEL PRIORS:

DO(1,3)rv\#_1-rv\#_8 IW $(1,15)$; ! retain small-variance priors for residual variances from ! baseline model (single-sample) in the multi-group analysis; $\mathrm{DO}(1,3)$ gives the range of values ! for the DO loop (i.e., the number of classes), whereas rv\#_1-rv\#_8 are the parameters to ! which to the priors (in parentheses) are attached; IW = inverse Wishart distribution (for an ! explanation of IW, see Muthén \& Asparouhov, 2012; DOI: 10.1037/a0026802)

DO $(1,3)$ cr\#_1-cr\#_28 IW $(0,15)$; ! retain small-variance priors for residual covariances from ! baseline model (single-sample) in the multi-group analysis

OUTPUT: STDYX TECH1 TECH8; 
"Cross-Cultural Invariance of the Mental Toughness Inventory Among Australian, Chinese, and Malaysian Athletes: A Bayesian Estimation Approach" by Gucciardi DF et al.

Journal of Sport \& Exercise Psychology

(C) 2016 Human Kinetics, Inc.

Table S7. Mplus syntax for exact zero metric invariance analysis of unidimensional mental toughness inventory with Bayesian estimation. (Note: code preceded by an exclamation mark is not read by Mplus when the run is executed).

TITLE: Cross-cultural invariance analyses of the MTI - exact metric invariance with Bayesian estimation

DATA: FILE = Combined data.csv;

VARIABLE: NAMES = country mti1 mti2 mti3 mti4 mti5 mti6 mti7 mti8;

KNOWNCLASS IS $\mathrm{g}$ (country $=0$ country $=1$ country=2);

CLASSES IS g(3);

USEVARIABLES = mti1 mti2 mti3 mti4 mti5 mti6 mti7 mti8;

MISSING = ALL (999);

MODEL:

\%overall\%

MT BY mti1* mti2 mti3 mti4 mti5 mti6 mti7 mti8 (fl1-fl8); ! constrains factor loadings to be ! equal across groups by specifying the labels fl1-fl18 [here is the difference with the exact

! configural invariance model depicted in Table S6]

MT@1;

[MT@0];

[mti1-mti8*] (nu\#_1-nu\#_8);

mti1-mti8 (rv\#_1-rv\#_8);

mti1-mti8 WITH mti1-mti8 (cr\#_1-cr\#_28);

ANALYSIS:

MODEL = allfree;

TYPE = mixture;

ESTIMATOR = BAYES;

PROCESSOR $=4$;

CHAINS $=4$;

FBITERATIONS = 150000;

MODEL PRIORS:

DO(1,3)rv\#_1-rv\#_8 IW $(1,15)$;

DO(1,3)cr\#_1-cr\#_28 IW $(0,15)$;

OUTPUT: STDYX TECH1 TECH8; 
"Cross-Cultural Invariance of the Mental Toughness Inventory Among Australian, Chinese, and Malaysian Athletes: A Bayesian Estimation Approach" by Gucciardi DF et al.

Journal of Sport \& Exercise Psychology

(C) 2016 Human Kinetics, Inc.

Table S8. Mplus syntax for exact zero scalar invariance analysis of unidimensional mental toughness inventory with Bayesian estimation. (Note: code preceded by an exclamation mark is not read by Mplus when the run is executed).

TITLE: Cross-cultural invariance analyses of the MTI - exact metric invariance with Bayesian estimation

DATA: FILE = Combined data.csv;

VARIABLE: NAMES = country mti1 mti2 mti3 mti4 mti5 mti6 mti7 mti8;

KNOWNCLASS IS $\mathrm{g}$ (country $=0$ country $=1$ country=2);

CLASSES IS g(3);

USEVARIABLES = mti1 mti2 mti3 mti4 mti5 mti6 mti7 mti8;

MISSING = ALL (999);

MODEL:

\%overall\%

MT BY mti1* mti2 mti3 mti4 mti5 mti6 mti7 mti8 (fl1-fl8);

MT@1;

[MT@0];

[mti1-mti8*] (nu1-nu8); ! constrains item intercepts to be equal across groups [here is the ! difference with the exact metric invariance model depicted in Table S7]

mti1-mti8 (rv\#_1-rv\#_8);

mti1-mti8 WITH mti1-mti8 (cr\#_1-cr\#_28);

ANALYSIS:

MODEL = allfree;

TYPE = mixture;

ESTIMATOR = BAYES;

PROCESSOR $=4$;

CHAINS $=4$;

FBITERATIONS = 150000;

MODEL PRIORS:

DO(1,3)rv\#_1-rv\#_8 IW $(1,15)$;

DO(1,3)cr\#_1-cr\#_28 IW $(0,15)$;

OUTPUT: STDYX TECH1 TECH8; 
"Cross-Cultural Invariance of the Mental Toughness Inventory Among Australian, Chinese, and Malaysian Athletes: A Bayesian Estimation Approach" by Gucciardi DF et al.

Journal of Sport \& Exercise Psychology

(c) 2016 Human Kinetics, Inc.

Table S9. Mplus syntax for approximate metric invariance analysis of unidimensional mental toughness inventory with Bayesian estimation. (Note: code preceded by an exclamation mark is not read by Mplus when the run is executed).

TITLE: Cross-cultural invariance analyses of the MTI - approximate metric invariance with Bayesian estimation

DATA: FILE = Combined data.csv;

VARIABLE: NAMES = country mti1 mti2 mti3 mti4 mti5 mti6 mti7 mti8;

KNOWNCLASS IS $\mathrm{g}$ (country $=0$ country $=1$ country=2);

CLASSES IS g(3);

USEVARIABLES = mti1 mti2 mti3 mti4 mti5 mti6 mti7 mti8;

MISSING = ALL (999);

MODEL:

$\%$ overall\%

MT BY mti1* mti2 mti3 mti4 mti5 mti6 mti7 mti8 (fl1-fl8);

MT@1;

[MT@0];

[mti1-mti8] (nu1-nu8);

mti1-mti8 (rv\#_1-rv\#_8);

mti1-mti8 WITH mti1-mti8 (cr\#_1-cr\#_28);

ANALYSIS:

MODEL = allfree;

TYPE = mixture;

ESTIMATOR = BAYES;

PROCESSOR $=4$;

CHAINS $=4$;

FBITERATIONS $=150000$;

MODEL PRIORS:

DO(1,3)rv\#_1-rv\#_8 IW $(1,15)$;

DO(1,3)cr\#_1-cr\#_28 IW $(0,15)$;

! below, we set the priors for differences in factor loading between groups with a normal

! distribution, mean of zero and prior variance of .05 (which can be altered using the

! exclamation marks for the 3 options)

! DIFF produces "modification indices" by flagging non-invariant items as significantly

! deviating from average

DO(1,8)DIFF(fl1_\#-fl3_\#) N(0,.05);

! DO(1,8)DIFF(fl1_\#-fl3_\#) N(0,.01);

! DO(1,8)DIFF(fl1_\#-fl3_\#) N(0,.005);

OUTPUT: STDYX TECH1 TECH8; 
"Cross-Cultural Invariance of the Mental Toughness Inventory Among Australian, Chinese, and Malaysian Athletes: A Bayesian Estimation Approach" by Gucciardi DF et al.

Journal of Sport \& Exercise Psychology

(C) 2016 Human Kinetics, Inc.

Table S10. Mplus syntax for approximate scalar invariance analysis of unidimensional mental toughness inventory with Bayesian estimation. (Note: code preceded by an exclamation mark is not read by Mplus when the run is executed).

TITLE: Cross-cultural invariance analyses of the MTI - approximate metric and scalar invariance with Bayesian estimation

DATA: FILE = Combined data.csv;

VARIABLE: NAMES = country mti1 mti2 mti3 mti4 mti5 mti6 mti7 mti8;

KNOWNCLASS IS $\mathrm{g}$ (country $=0$ country $=1$ country $=2$ );

CLASSES IS g(3);

USEVARIABLES = mti $1 \mathrm{mti} 2 \mathrm{mti} 3 \mathrm{mti} 4 \mathrm{mti} 5 \mathrm{mti} 6 \mathrm{mti} 7 \mathrm{mti}$;

MISSING = ALL (999);

MODEL:

\%overall\%

MT BY mti1* mti2 mti3 mti4 mti5 mti6 mti7 mti8 (fl1-fl8);

MT@1;

[MT@0];

[mti1-mti8] (nu1-nu8);

mti1-mti8 (rv\#_1-rv\#_8);

mti1-mti8 WITH mti1-mti8 (cr\#_1-cr\#_28);

ANALYSIS:

MODEL = allfree;

TYPE = mixture;

ESTIMATOR = BAYES;

PROCESSOR $=4$;

CHAINS $=4$;

FBITERATIONS $=150000$

MODEL PRIORS:

DO(1,3)rv\#_1-rv\#_8 IW $(1,15)$;

DO(1,3)cr\#_1-cr\#_28 IW $(0,15)$;

! below, we set the priors for differences in factor loading between groups with a normal

! distribution, mean of zero and prior variance of .05 (which can be altered using the

! exclamation marks for the 3 options)

! DIFF produces "modification indices" by flagging non-invariant items as significantly

! deviating from average

DO(1,8)DIFF(fl1_\#-fl3_\#) N(0,.05);

! DO(1,8)DIFF(fl1_\#-fl3_\#) N(0,.01);

! DO $(1,8)$ DIFF(fl1_\#-fl3_\#) N(0,.005);

! below, we set the priors for item intercept differences with a normal distribution, mean of zero

! and prior variance of .05 (which can be altered using the exclamation marks for the 3 options)

DO(1,8)DIFF(nu1_\#-nu3_\#) N(0,.05);

! DO $(1,8) \operatorname{DIFF}($ nu1_\#-nu3_\#) N $(0, .01)$;

! DO(1,8)DIFF(nu1_\#-nu3_\#) N(0,.005);

OUTPUT: STDYX TECH1 TECH8; 
"Cross-Cultural Invariance of the Mental Toughness Inventory Among Australian, Chinese, and Malaysian Athletes: A Bayesian Estimation Approach" by Gucciardi DF et al.

Journal of Sport \& Exercise Psychology

(C) 2016 Human Kinetics, Inc.

Table S11. Mplus syntax for 'partial measurement' invariance analysis of unidimensional mental toughness inventory with Bayesian estimation. (Note: code preceded by an exclamation mark is not read by Mplus when the run is executed).

TITLE: Cross-cultural invariance analyses of the MTI - partial measurement invariance with Bayesian estimation (Step 2 as recommended by Muthén and Asparouhov, 2013)

DATA: FILE = Combined data.csv;

VARIABLE: NAMES = country mti1 mti2 mti3 mti4 mti5 mti6 mti7 mti8;

KNOWNCLASS IS g(country $=0$ country $=1$ country $=2$ );

CLASSES IS g(3);

USEVARIABLES = mti $1 \mathrm{mti} 2 \mathrm{mti} 3 \mathrm{mti} 4 \mathrm{mti} 5 \mathrm{mti} 6 \mathrm{mti} 7 \mathrm{mti}$;

MISSING = ALL (999);

MODEL:

\%overall\%

MT BY mti1* mti2 mti3 mti4 mti5 mti6 mti7 mti8 (fl1-fl8);

MT@1;

[MT@0];

[mti1-mti8] (nu1-nu8);

mti1-mti8 (rv\#_1-rv\#_8);

mti1-mti8 WITH mti1-mti8 (cr\#_1-cr\#_28);

$\% \mathrm{g \# 2} \%$ ! class specific information for the Malaysian athletes; code in this section will differ

! what is captured in the overall model above (\%overall\%)

MT@1;

[mti1 mti3 mti4 mti7 mti8]; ! releases the equality constraint for these item intercepts in the

! Malaysian athletes

$\% \mathrm{g \# 3 \%}$ ! class specific information for the Chinese athletes; code in this section will differ

! what is captured in the overall model above (\%overall\%)

MT@1;

[mti5 mti6 mti7 mti8]; ! releases the equality constraint for these item intercepts in the

! Chinese athletes

ANALYSIS:

MODEL = allfree;

TYPE = mixture;

ESTIMATOR $=$ BAYES;

PROCESSOR $=4$;

CHAINS $=4$;

FBITERATIONS $=150000$;

MODEL PRIORS:

DO(1,3)rv\#_1-rv\#_8 IW $(1,15)$;

DO $(1,3)$ cr\#_1-cr\#_28 IW $(0,15)$;

OUTPUT: STDYX TECH1 TECH8; 